\title{
Characteristics of gravity waves generated in the jet-front system in a baroclinic instability simulation
}

\author{
Young-Ha Kim ${ }^{1, \text { a }}$, Hye-Yeong Chun ${ }^{1}$, Sang-Hun Park ${ }^{2}$, In-Sun Song ${ }^{3}$, and Hyun-Joo Choi ${ }^{4}$ \\ ${ }^{1}$ Department of Atmospheric Sciences, Yonsei University, Seoul, Korea \\ ${ }^{2}$ National Center for Atmospheric Research, Boulder, Colorado, USA \\ ${ }^{3}$ Korea Polar Research Institute, Incheon, Korea \\ ${ }^{4}$ Korea Institute of Atmospheric Prediction Systems, Seoul, Korea \\ a now at: Department of Atmospheric Science and Engineering, Ewha Womans University, Seoul, Korea \\ Correspondence to: Hye-Yeong Chun (chunhy@yonsei.ac.kr)
}

Received: 24 October 2015 - Published in Atmos. Chem. Phys. Discuss.: 19 November 2015

Revised: 1 March 2016 - Accepted: 10 April 2016 - Published: 19 April 2016

\begin{abstract}
An idealized baroclinic instability case is simulated using a $\sim 10 \mathrm{~km}$ resolution global model to investigate the characteristics of gravity waves generated in the baroclinic life cycle. Three groups of gravity waves appear around the high-latitude surface trough at the mature stage of the baroclinic wave. They have horizontal and vertical wavelengths of $40-400$ and $2.9-9.8 \mathrm{~km}$, respectively, in the upper troposphere. The two-dimensional phase-velocity spectrum of the waves is arc shaped with a peak at $17 \mathrm{~m} \mathrm{~s}^{-1}$ eastward. These waves have difficulty in propagating upward through the tropospheric westerly jet. At the breaking stage of the baroclinic wave, a midlatitude surface low is isolated from the higher-latitude trough, and two groups of quasistationary gravity waves appear near the surface low. These waves have horizontal and vertical wavelengths of 60-400 and $4.9-14 \mathrm{~km}$, respectively, and are able to propagate vertically for long distances. The simulated gravity waves seem to be generated by surface fronts, given that the structures and speeds of wave phases are coherent with those of the fronts.
\end{abstract}

\section{Introduction}

Gravity waves (GWs) at high latitudes have a significant impact on the shape and magnitude of the polar jet in the middle atmosphere by large-scale deposition of the momentum that they transport (Kim et al., 2003). Because the horizontal scale of gravity waves is about $10-1000 \mathrm{~km}$, they are not properly represented in numerical models with grid sizes similar to or larger than $1^{\circ}$ and should be parameterized. Mountains are one of the main sources of GWs at high latitudes and have been parameterized in global models for a long time (e.g., Palmer et al., 1986). However, the momentum deposited by mountain GW parameterization does not fully account for the momentum required to reproduce the observed polar jet structure in models (e.g., Sato et al., 2012; Choi and Chun, 2013). Moreover, in the summer, mountain GWs are difficult to propagate to the stratosphere, which has the easterly jet, because they are stationary waves.

Jet-front systems have been considered as a feasible source of high-latitude GWs, since many observations have revealed enhanced GW activities near the jets and fronts (e.g., Uccellini and Koch, 1987; Fritts and Nastrom, 1992; Eckermann and Vincent, 1993; Guest et al., 2000). Several mechanisms of GW excitation in jet-front systems have been proposed, including spontaneous balanced adjustment, Lighthill radiation, unbalanced instability, and shear instability (see Plougonven and Zhang, 2014, and references therein). Further investigation of these proposed mechanisms is still ongoing to understand GW generation. Jet-front GWs have been observed to have horizontal wavelengths of about 50 $500 \mathrm{~km}$, vertical wavelengths of $1-7 \mathrm{~km}$, and typical intrinsic frequencies of $\sim 1-3 f$, where $f$ is the Coriolis parameter (Uccellini and Koch, 1987; Guest et al., 2000; Plougonven et al., 2003). Note that the GW characteristics estimated from measurements have some uncertainties because each measurement can detect only a portion of waves and the analysis 
methods used to estimate the characteristics (e.g., hodograph analysis) include uncertainties (Zhang et al., 2004).

Jet-front GWs have been simulated using mesoscale models to study their generation, propagation, and characteristics. Because the jet-front systems are likely to associate with baroclinic waves and their instability, modeling studies have often involved simulating baroclinic life cycles (e.g., O'Sullivan and Dunkerton, 1995; Zhang, 2004; Plougonven and Snyder, 2007; Mirzaei et al., 2014). Zhang (2004) simulated an idealized baroclinic life cycle associated with uppertropospheric jet-front systems using a high-resolution model. He detected vertically propagating GWs with horizontal and vertical wavelengths of $\sim 100-200 \mathrm{~km}$ and $\sim 2.5 \mathrm{~km}$, respectively, which originate from the upper-tropospheric jet exit region. Wang and Zhang (2007) extended the work of Zhang (2004) and showed that the characteristics of the GWs near the upper-tropospheric jet exit vary depending on the baroclinicity. They demonstrated that the growth rate of the flow imbalance is correlated with that of the baroclinic wave and the intrinsic frequency of the GWs at the same time. Plougonven and Snyder (2007, PS07 hereafter) simulated standard (cyclonic) and anticyclonic life cycles of baroclinic instability. In the standard life cycle, GWs are excited from the upper-level jet exit region, which is consistent with the other studies discussed above, with horizontal and vertical wavelengths of about 210 and $1.1-1.5 \mathrm{~km}$, respectively. In the anticyclonic life cycle, GWs are emitted just ahead of the surface front with a large vertical wavelength $(\sim 6.4 \mathrm{~km})$.

From the perspective of parameterizing jet-front GWs, it is important to know the spectral shapes of the waves. In practice, the horizontal phase-velocity spectrum (or verticalwavenumber spectrum with respect to the phase direction) is crucial information for GW parameterizations, among other wave characteristics. Previous studies have reported on the dominant phase velocities of the GWs simulated in jet-front systems. For example, Wang and Zhang (2007) showed that the dominant phase speed of the GWs in their four simulations ranged from 0 to $11 \mathrm{~m} \mathrm{~s}^{-1}$ in directions perpendicular to the background flow. PS07 showed that the zonal phase speeds of the GWs in their simulations were about 13$15 \mathrm{~m} \mathrm{~s}^{-1}$. The phase speed appears to significantly vary depending on the case and particularly the model resolution of simulations. PS07 also highlighted that the phase speed of the GWs is the same as that of the baroclinic wave in both the cyclonic and anticyclonic wave cases (see also O'Sullivan and Dunkerton, 1995). If this is also true in other cases, it may be a hint to expecting the peak of the phase-velocity spectrum of GWs generated in baroclinic jet-front systems. The shapes of phase-velocity spectrum, e.g., the spectral width and dependency on the phase direction, have not been investigated enough.

It is notable that most of the recent studies regarding GWs in (standard) baroclinic life cycles, including those described previously, considered jet-front systems in which the baroclinic wave grew fast and had large amplitudes in the upper troposphere. Provided that the GWs excited near the surface can have a large vertical wavelength (PS07) and thus have the potential to propagate far vertically, low-level baroclinic instability cases are also of interest. In this study, we investigate the spectral characteristics of GWs simulated in an idealized low-level baroclinic instability case. Section 2 describes the experiment and GW detection method. Section 3.1 describes the overall features of the simulated baroclinic wave evolution. Section 3.2 presents the GW characteristics in the upper troposphere, and Sect. 3.3 presents aspects of the upward propagation of the waves. The origins of the GWs are discussed in Sect. 4, and Sect. 5 summarizes the study.

\section{Experiment and analysis method}

The idealized baroclinic instability case of Jablonowski and Williamson (2006, JW06 hereafter) is simulated using the global version of the Advanced Research Weather Research and Forecasting Model (WRF). The zonally symmetric, balanced component of the initial values of the variables in this case is illustrated in Fig. 1 in JW06. Note that the meridional gradient of the temperature and the vertical shear are maximal at the surface at $45^{\circ}$ and decreased with height (for the geometric height-based wind profile, see also Fig. 2 in Park et al., 2013). The peak of the zonal wind is at about $z \sim 11 \mathrm{~km}$ with a speed of $35 \mathrm{~m} \mathrm{~s}^{-1}$. The topography and moisture are not included in this case, which eliminates the possibility of GW generation by topography or diabatic heating. Thus, the GWs in this simulation are generated internally.

Previous studies on GWs in baroclinic life-cycle simulations have often used nested domains (e.g., Wang and Zhang, 2007) because these simulations require simultaneously large coverage of the domain to model the synopticscale baroclinic waves and high resolutions to capture the GWs. However, Park et al. (2014) highlighted that nesting can induce spurious reflection and distortion of waves from lateral boundaries. In addition, PS07 noted that numerical artifacts can potentially be included in the nested fields of variables when the fields are transited from one domain to another. In our study, high-resolution global simulation is performed without nesting in order to prevent such numerical artifacts and other potential problems arising at lateral boundaries.

The model uses horizontally uniform grids in latitudelongitude coordinates with a resolution of approximately $0.09^{\circ}\left(\sim 10 \mathrm{~km}\right.$ at the equator and $\sim 7.3 \mathrm{~km}$ at $\left.45^{\circ}\right)$. Fifty levels are used from the surface to $10 \mathrm{hPa}(\sim 31 \mathrm{~km})$, including the sponge layer at the uppermost $5 \mathrm{~km}$. The third-order Runge-Kutta integration scheme is used with a time step of $30 \mathrm{~s}$. The simulation is initialized by a small-amplitude sinusoidal perturbation with a zonal wavenumber of 9 at $\sim 50^{\circ} \mathrm{N}$, which triggers the growth of the baroclinic wave with the same wavenumber (for details on the initialization, 


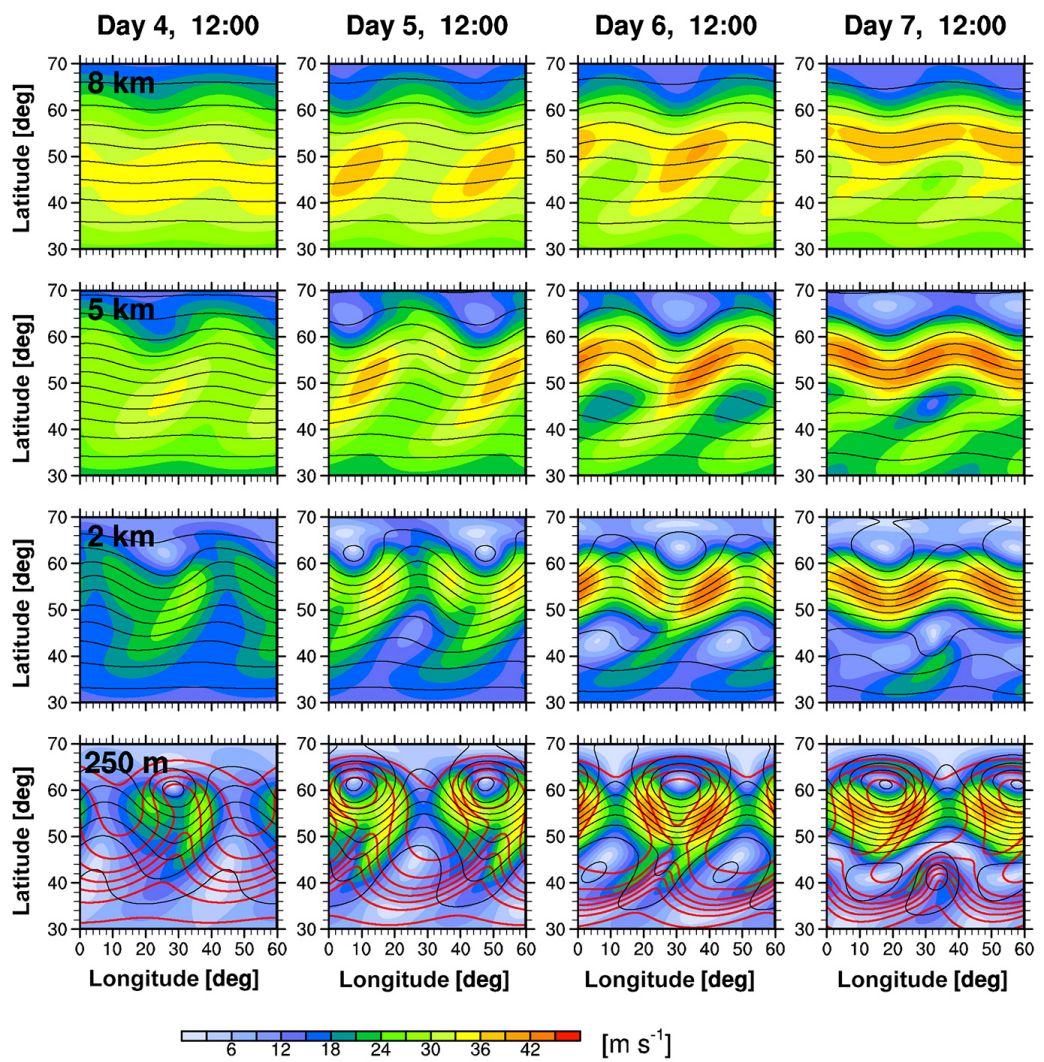

Figure 1. Background fields of the pressure (black contour) and horizontal wind speed (shading) at $z=0.25,2,5$, and $8 \mathrm{~km}$ (from bottom to top) on days $4,5,6$, and 7 at 12:00 UTC (from left to right). The background potential temperature is also plotted at $z=0.25 \mathrm{~km}$ (red contour). The contour intervals for the pressure and potential temperature are $8 \mathrm{hPa}$ and $8 \mathrm{~K}$, respectively.

refer to Park et al., 2013, where the simulations similar to here were performed but using different models and resolutions). Therefore, the simulation results are essentially symmetric for every $40^{\circ}$ in longitude. The results are saved every 5 min from day 4, when the GWs begin to appear with negligibly small amplitudes.

In this study, the large-scale background flow is defined for every variable at each grid point and time as a running average over the area bounded by the great-circle distance $\left(r_{\mathrm{a}}\right)$ of $300 \mathrm{~km}$ from the grid point at each instant. Then, the perturbation is defined as a departure from the background field. The averaging area to obtain the background and perturbation fields with $r_{\mathrm{a}}=300 \mathrm{~km}$ is about $2.8 \times 10^{5} \mathrm{~km}^{2}$, which is comparable to that of previous modeling studies on mesoscale GWs (e.g., Kim and Chun, 2010). We confirmed that the perturbation contains waves with horizontal wavelengths of smaller than $\sim 2000 \mathrm{~km}$ (not shown). The waves with these scales include almost the entire spectrum of GWs and a small portion of the baroclinic wave. A larger value of $r_{\mathrm{a}}$ than $300 \mathrm{~km}$ results in a larger portion of the baroclinic wave in the perturbation fields, whereas a smaller value causes some portions of the GWs to be eliminated from the perturbations. In our case, the amplitude of the baroclinic wave is small in the upper troposphere, as described in the next section. In particular, the baroclinic-wave amplitude in the vertical-velocity perturbation in the upper troposphere is negligible when $r_{\mathrm{a}}=300 \mathrm{~km}$. The characteristics of the GWs are analyzed in the upper troposphere using the vertical-velocity perturbation, as described in Sect. 3.

\section{Results}

\subsection{Description of the baroclinic wave}

This section briefly describes the features of the simulated baroclinic wave before presenting the analysis of the GWs. Figure 1 shows the background fields of the pressure and horizontal wind speed at $z=0.25,2,5$, and $8 \mathrm{~km}$ from days 4 to 7 along with the $250 \mathrm{~m}$ background potential temperature. On day 4, the baroclinic wave is in the developing stage and has a maximum amplitude at $50-60^{\circ} \mathrm{N}$ at $250 \mathrm{~m}$ for the pressure $(15 \mathrm{hPa})$ and potential temperature $(14 \mathrm{~K})$. As the wave grows, a low-level jet develops at $45-60^{\circ} \mathrm{N}$ on the western and eastern sides of the trough. On day 5 , the wave reaches the mature stage. The warm core at about $60^{\circ} \mathrm{N}$ begins to be isolated from the front at lower latitudes by the low-level jet. During the developing and mature stages of the wave, the 

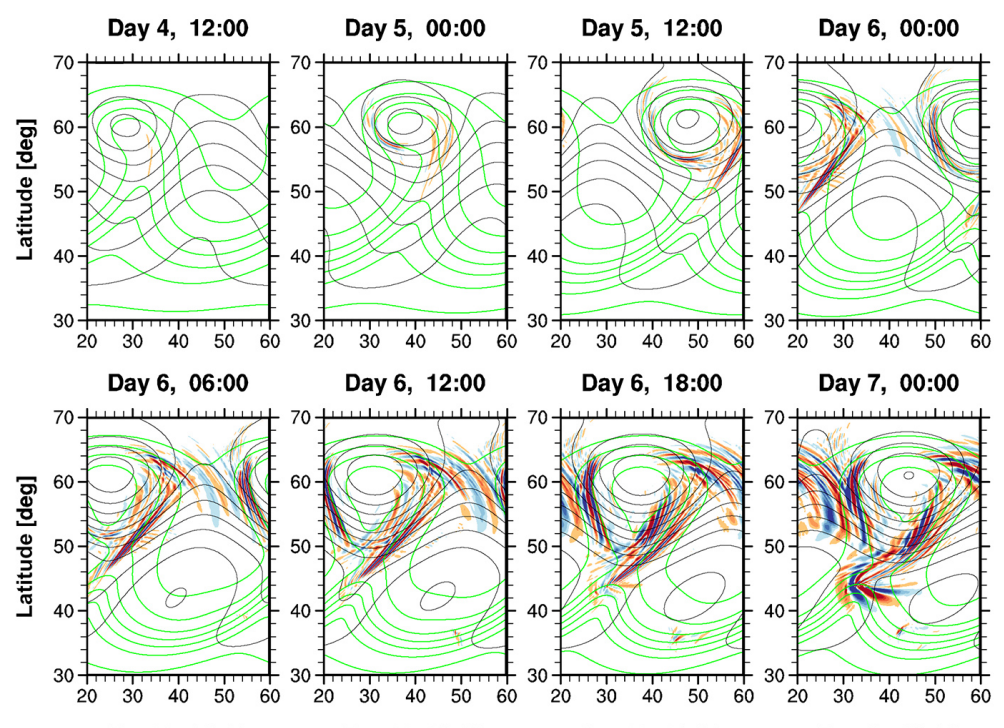

Day 6, 18:00

Day 7, 00:00
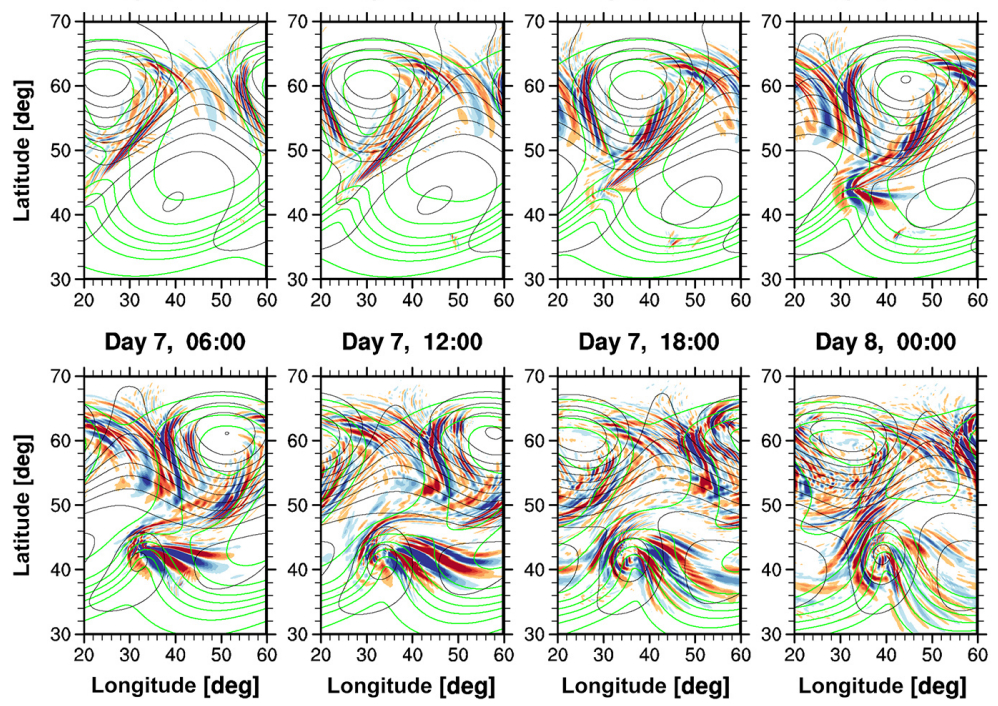

Day 8, 00:00
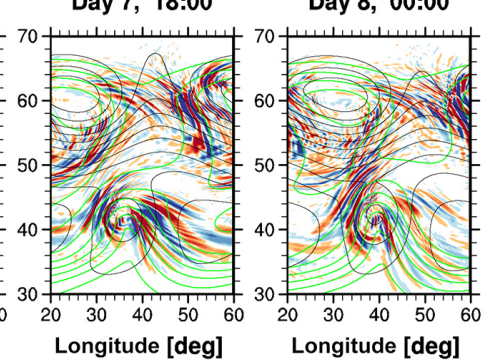

$\begin{array}{llllllllllll}15 & -12 & -9 & -6 & \frac{1}{1} & \frac{1}{1} & \frac{1}{1} & \frac{1}{1} & \frac{1}{12} & 15\end{array}\left[\mathrm{~mm} \mathrm{~s}^{-1}\right]$

Figure 2. Perturbation vertical velocity $\left(w^{\prime}\right)$ at $z=8 \mathrm{~km}$ (shading) superimposed on the $250 \mathrm{~m}$ background pressure (black) and potential temperature (green) from 12:00 UTC on day 4 to 00:00 UTC on day 8. The figures are shown with 12 h intervals before 00:00 UTC on day 6 and with $6 \mathrm{~h}$ intervals afterward. The contour intervals for the pressure and potential temperature are $8 \mathrm{hPa}$ and $8 \mathrm{~K}$, respectively.

upper-level perturbations have much smaller amplitudes than below, although they grow gradually. On day 6, the breaking stage of the wave, the $250 \mathrm{~m}$ pressure pattern exhibits a meridionally overturned structure around $42^{\circ} \mathrm{N}, 16^{\circ} \mathrm{E}$. The trough at this latitude grows away from the higher-latitude trough and becomes isolated on day 7. This secondary low moves much slower than the higher-latitude wave. In particular, it is almost fixed at $31-33^{\circ} \mathrm{E}$ between 00:00 and 12:00 UTC on day 7 (see Fig. 2). At $50-58^{\circ} \mathrm{N}$, the pressure gradient becomes large, which results in a strong westerly jet in the lower to middle troposphere (days 6 and 7). The magnitude of the jet constructed during the breaking stage of the wave reaches about $45 \mathrm{~m} \mathrm{~s}^{-1}$ at $5 \mathrm{~km}$ on day 7 (Fig. 1).

\subsection{Characteristics of GWs}

Figure 2 shows the evolution of the perturbation vertical velocity $\left(w^{\prime}\right)$ at $8 \mathrm{~km}$ from days 4 to 8 , superimposed on the $250 \mathrm{~m}$ background pressure and potential temperature. The perturbations at $8 \mathrm{~km}$ appear on day 5 at $50-62^{\circ} \mathrm{N}$ above the low-level trough with a small magnitude. The magnitude in- creases with time, and some organized structures of wave packets are found after 12:00 UTC on day 5 at the western and eastern parts of the trough. These packets are identified as gravity waves based on their horizontal wavelength scale $(\sim 100 \mathrm{~km})$. On day 6 , three major groups of GWs are found with large amplitudes: with a southeastward wave vector at the eastern part of the low-level trough $\left(50^{\circ} \mathrm{N}, 35^{\circ} \mathrm{E}\right.$ at 12:00 UTC) (W1), with a eastward wave vector at the western part of the trough $\left(58^{\circ} \mathrm{N}, 20^{\circ} \mathrm{E}\right)(\mathrm{W} 2)$, and with a northeastward wave vector over the regions from the eastern part of the trough to the ridge $\left(62^{\circ} \mathrm{N}, 45^{\circ} \mathrm{E}\right)(\mathrm{W} 3)$. Their locations relative to the phase of the low-level baroclinic waves are maintained throughout the simulation. The overall structure of the wave packets northward of about $50^{\circ} \mathrm{N}$ is also qualitatively maintained until around 12:00 UTC on day 7 by exhibiting the three distinct wave-vector directions. It becomes complex afterward (Fig. 2). Note that the phase lines of $\mathrm{W} 1$ and $\mathrm{W} 2$ are almost parallel to the isentropic lines at $250 \mathrm{~m}$ until at least 12:00 UTC on day 7. In particular, the shape of the phase lines of W2 changes following the change in the isentropic lines during the $\sim 24 \mathrm{~h}$ period from 
(a)
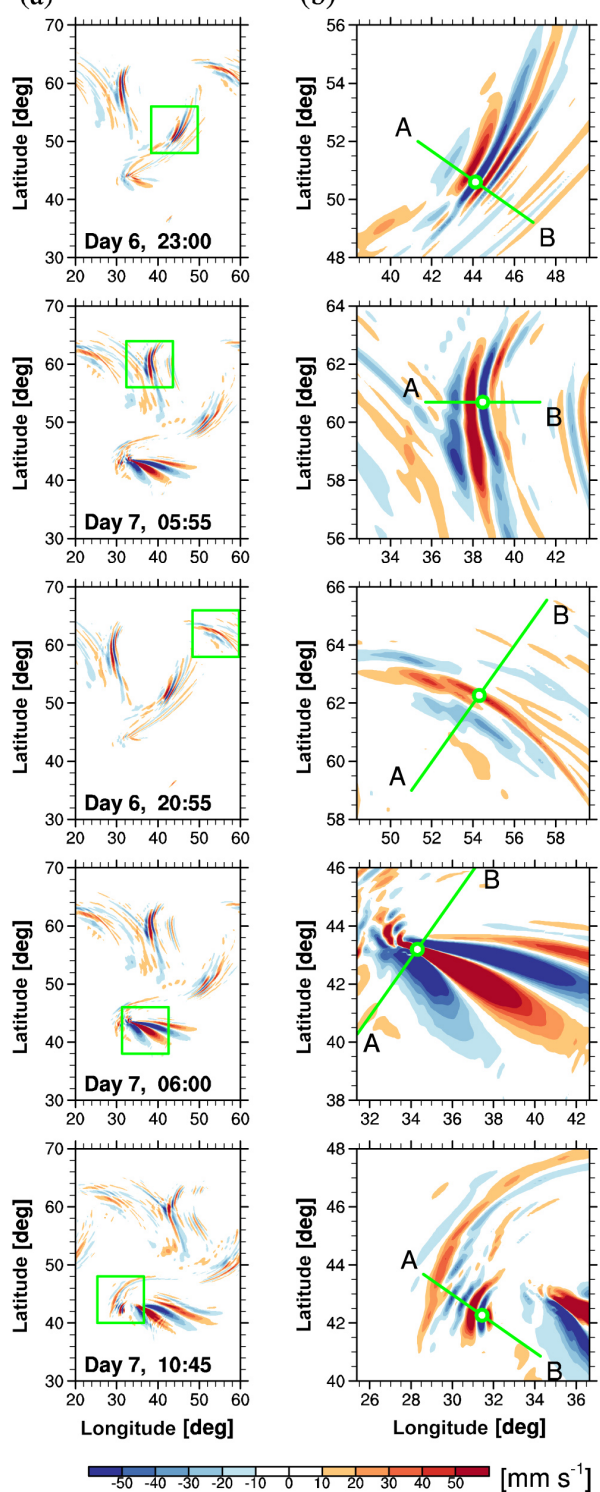

(b)
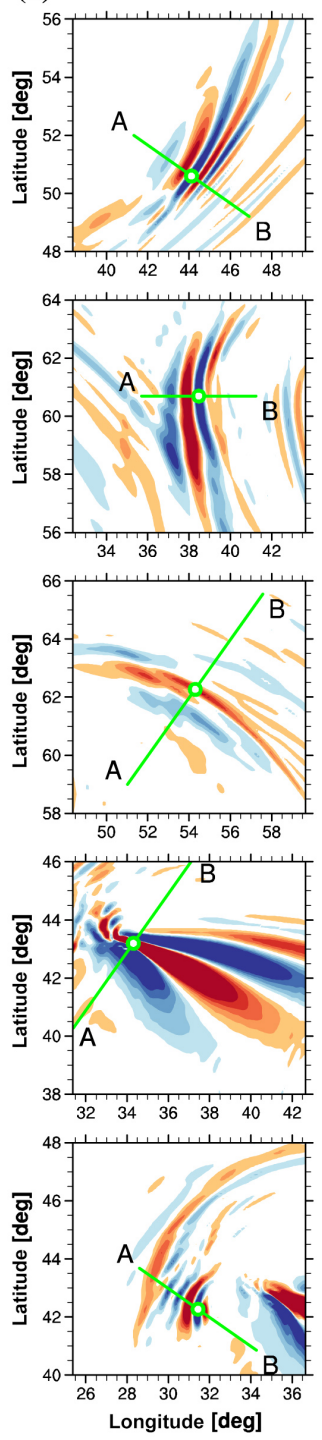

$\left[\mathrm{mm} \mathrm{s}^{-1}\right]$ (c)
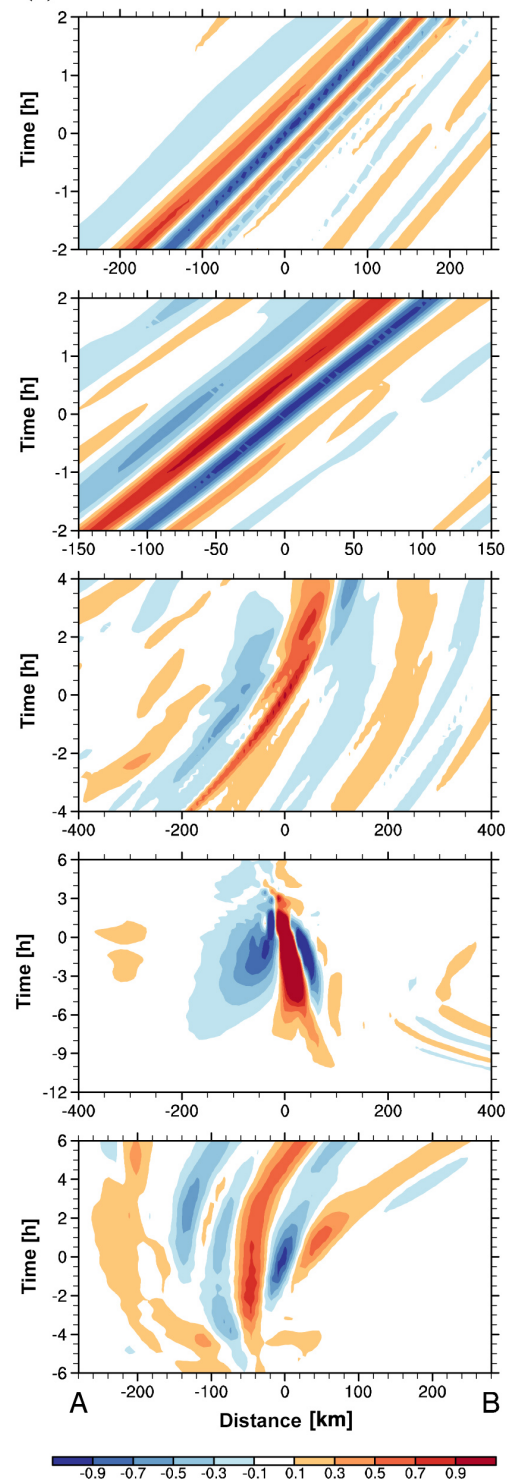

Figure 3. (a) $w^{\prime}$ at $z=8 \mathrm{~km}$ when the magnitude of $w^{\prime}$ is largest for each of the five wave groups (W1-W5, see the text) (from top to bottom) and (b) enlargements of the green boxes in (a). (c) Cross sections of $w^{\prime}$ along the green lines in (b) with respect to the time relative to the instants in (a) and (b). $w^{\prime}$ in (c) is normalized by its maximum, and the normalized $w^{\prime}$ for W4 is further divided by 5 for display purposes.

12:00 UTC on day 5 when the warm core at $60^{\circ} \mathrm{N}$ is isolated. This is not the case for W3. A possible reason for these is discussed later.

On day 7, other wave groups are detected at around $42^{\circ} \mathrm{N}$, where the secondary low is isolated and developed near the surface. One of these is located to the east of the low with a north-northeastward wave vector (W4), and the other is to the northwest of the low with a east-southeastward wave vector (W5). For W4, the amplitude increases with time until around 12:00 UTC on day 7 and decreases afterward, while the amplitude of W5 seems to increase steadily. W5 has a complex structure that changes significantly with time.
When the secondary low is located west of the high-latitude trough (00:00 and 00:06 UTC on day 7), the northeastern part of W4 is overlapped with the southwestern part of W1, while they are well separated when the secondary low is east of the high-latitude trough (18:00 UTC on day 7). Note that W5 after 12:00 UTC on day 7 resembles the GWs generated by the surface cold front in an anticyclonic baroclinic wave simulation by PS07 (see their Fig. 10).

Figure 3 a shows the horizontal fields of $w^{\prime}$ when the magnitude of $w^{\prime}$ is largest in each location of W1-W5, and Fig. $3 \mathrm{~b}$ shows their close-up views. The location of the $\left|w^{\prime}\right|$ maximum is indicated by the green circle in Fig. 3b. The 


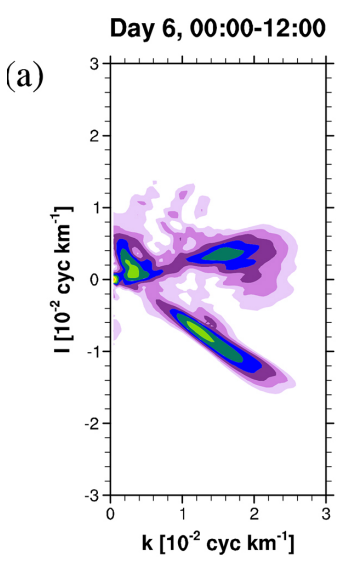

Day 6, 12:00-24:00

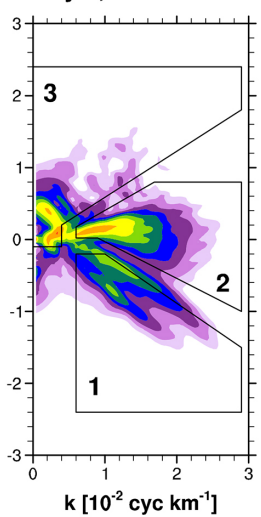

Day 7, 00:00-12:00

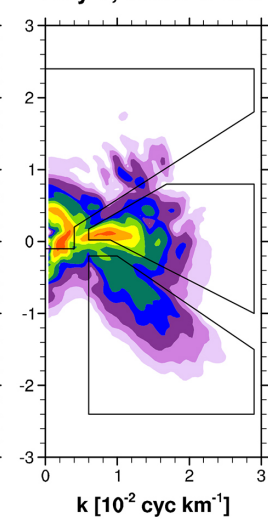

Day 7, 12:00-24:00

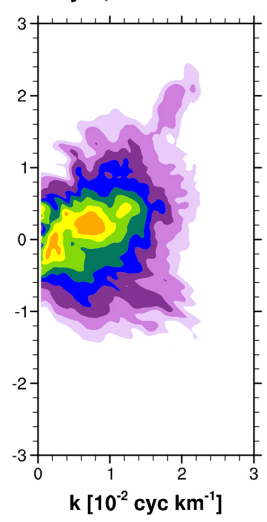

(b)

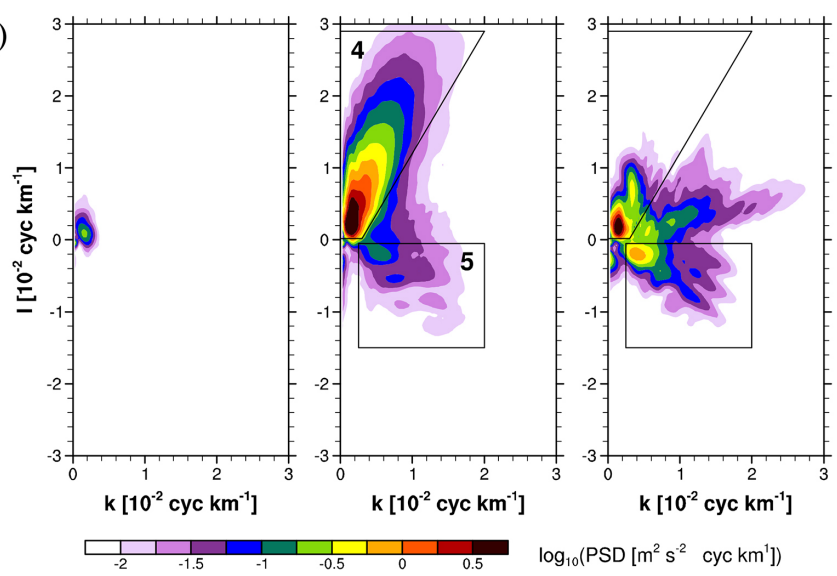

Figure 4. Twelve-hour averaged power spectra of $w^{\prime}$ at $z=8 \mathrm{~km}$ as a function of zonal and meridional wavenumbers calculated in (a) $48-$ $73^{\circ} \mathrm{N}, 20-60^{\circ} \mathrm{E}$ and (b) $21-46^{\circ} \mathrm{N}, 20-60^{\circ} \mathrm{E}$ from day 6 to day 8 (from left to right). In (b), the plot for 00:00-12:00 UTC on day 6 is omitted.

horizontal wavelengths of the GWs, measured by the distance between two adjacent constant phase lines, are approximately 70, 60, 200, 60, and $80 \mathrm{~km}$ for W1-W5, respectively, near the $\left|w^{\prime}\right|$ maximum. Figure $3 \mathrm{c}$ shows the time series of $\left|w^{\prime}\right|$ along the horizontal line that passes the $\left|w^{\prime}\right|$ maximum in the direction of wave vector (green line in Fig. 3b). The phase speeds of the GWs near the $\left|w^{\prime}\right|$ maximum, measured by the slope of the phase line at the origin in Fig. 3c, are about $19,15,10,1.5$, and $2.3 \mathrm{~m} \mathrm{~s}^{-1}$ for W1-W5, respectively. Their periods corresponding to the horizontal wavelengths and phase speeds are $60,70,330,670$, and $580 \mathrm{~min}$, respectively. The vertical wavelengths are also estimated in a similar manner in vertical cross sections (not shown). W1-W5 have vertical wavelengths of 4.5-5, 4.5-5.5, 4-5, 6-6.5, and $9-12 \mathrm{~km}$, respectively. It should be noted that the wave characteristics obtained here can vary significantly depending on when and where the two adjacent phase lines are defined. For example, the horizontal wavelength of W4 varies significantly with the location (Fig. 3b), and the phase speeds of W3 and W5 vary with time (Fig. 3c). This implies that the characteristics of the simulated waves may have broad spectra.
The horizontal wavelength spectra of the five groups of GWs are investigated using the Fourier spectral method. The first three groups (W1, W2, and W3) are analyzed by the two-dimensional Fourier transform of $w^{\prime}$ at $8 \mathrm{~km}$ in the domain of $48-73^{\circ} \mathrm{N}, 20-60^{\circ} \mathrm{E}$ (D1) to the $(k, l)$ space, where $k$ and $l$ are the zonal and meridional wavenumbers, respectively. Here, the longitudinal band of $20-60^{\circ} \mathrm{E}$ is chosen because the simulation results are symmetric for every $40^{\circ}$ in longitude, as mentioned in Sect. 2. Figure 4a shows the power spectral density (PSD) of the $8 \mathrm{~km} w^{\prime}$ in D1, averaged over $12 \mathrm{~h}$. At 00:00-12:00 UTC on day 6, the PSD exhibits three distinct peaks at $(k, l)=(1.2,-0.7),(1.6,0.3)$, and $(0.3,0.2) \times 10^{-2}$ cycle km${ }^{-1}$. Note that the directions of the wave vector $(k, l)$ for each of the three peaks correspond to those for W1, W2, and W3 in Fig. 2, respectively. After 12:00 UTC on day 6 , the overall magnitude of the PSD increases, and it is maximal at 00:00-12:00 UTC on day 7. Afterward, the three peaks become less distinguishable than before.

Based on the spectral shapes of the three peaks, we decompose the spectral domain into three parts, as indicated in Fig. 4a, in order to separate the wave groups W1-W3. 
(a) Day 7, 00:00
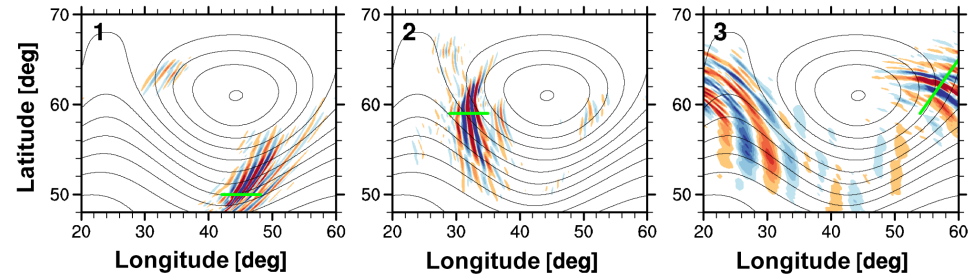

(b) Day 7, 12:00

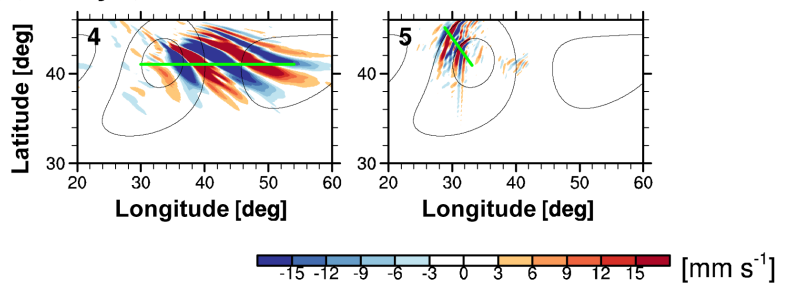

Figure 5. $w^{\prime}$ at $z=8 \mathrm{~km}$ (shading) (a) at 00:00 UTC on day 7, reconstructed from the three spectral domains (1-3) indicated in Fig. 4a, and (b) at 12:00 UTC on day 7, from the two spectral domains (4 and 5) in Fig. 4b. The background pressure at $250 \mathrm{~m}$ is superimposed (contour) with intervals of $8 \mathrm{hPa}$. The green lines indicate the axes along which the vertical cross sections are shown in Fig. 11 .

The decomposition is performed for the $24 \mathrm{~h}$ period from 12:00 UTC on day 6 , during which the wave amplitude is large and the spatial and spectral structures of the waves are maintained with time (Figs. 2 and 4a). The spectral components around $(k, l) \sim(0.1,-0.3) \times 10^{-2}$ cycle km${ }^{-1}$ are not included in any of the decomposed domains. In addition, there are gaps between the decomposed domains. We did not analyze these spectral components, because they represented more than one wave group (not shown). Figure 5a shows the $8 \mathrm{~km} w^{\prime}$ reconstructed for each of the three decomposed spectral domains. The three reconstructed fields are confirmed to capture the major characteristics of W1, W2, and W3. For example, the waves are reconstructed with horizontal wavelengths similar to those shown in Fig. 2. The amplitude of the reconstructed waves is about $89 \%$ of that of the waves in D1 in Fig. 2. This reduction in amplitude is expected owing to the gaps between the decomposed spectral domains (Fig. 4a). In addition, W2 and the eastern part of W3, which overlaps with each other with significant amplitudes (e.g., at around $56^{\circ} \mathrm{N}, 32^{\circ} \mathrm{E}$ at 00:00 UTC on day 7; see Fig. 2), are well separated in the reconstructed fields (Fig. 5a).

Figure 6 shows PSDs of the decomposed waves as a function of horizontal wavelength. W1 and W2 have similar wavelengths of $40-110$ and $50-120 \mathrm{~km}$, respectively, with primary peaks at about $80 \mathrm{~km}$ for both. Here, the range of the wavelengths (and the ranges of other characteristics that are investigated afterward) is determined so that the waves within that range represent $80 \%$ of the total variance for each wave group (i.e., the variance by the waves with wavelengths larger than the upper limit is $10 \%$ of the total and vice versa for the lower limit). W3 has larger wavelengths $(70-400 \mathrm{~km}$ with a peak at $250 \mathrm{~km})$ than $\mathrm{W} 1$ and W2. Pre-

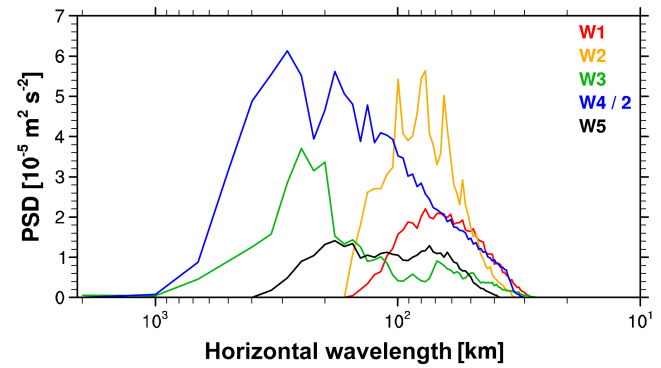

Figure 6. Horizontal-wavelength power spectra of $w^{\prime}$ at $z=8 \mathrm{~km}$ averaged over $24 \mathrm{~h}$ from 12:00 UTC on day 6 for W1 (red), W2 (yellow), and W3 (green) and from 00:00 UTC on day 7 for W4 (blue) and W5 (black). The spectra for W1-W5 were obtained from the spectral domains 1-5 indicated in Fig. 4, respectively. For W4, the power spectrum is divided by 2 .

vious studies have shown that the horizontal wavelengths of GWs simulated in dry baroclinic life cycles range from about 80 to $300 \mathrm{~km}$ when models with horizontal resolutions of approximately $10 \mathrm{~km}$ or finer are used (Zhang, 2004; Wang and Zhang, 2007; Waite and Snyder, 2009; Mirzaei et al., 2014). Based on the spectral peaks shown in Fig. 6, the horizontal wavelengths of the GWs simulated in our case are in the range obtained from the previous studies.

W4 and W5 are analyzed in the same way as W1-W3. Figure $4 \mathrm{~b}$ shows the PSD of the $8 \mathrm{~km} w^{\prime}$ in $21-46^{\circ} \mathrm{N}, 20$ $60^{\circ} \mathrm{E}$ (D2) as a function of $k$ and $l$. Here, we do not include latitudes higher than $46^{\circ} \mathrm{N}$ into $\mathrm{D} 2$, although a nonnegligible portion of W5 is sometimes located there (e.g., at 00:00 UTC on day 8; Fig. 2). At those latitudes, W5 and the southwestern edge of W1 are co-located with similar wave vectors. Thus, it is not easy to separate the two wave 
Table 1. Characteristics of the five groups of simulated gravity waves at $z=8 \mathrm{~km}$. The values in bold indicate the primary peaks obtained from the spectra for each characteristic.

\begin{tabular}{llllll}
\hline & W1 & W2 & W3 & W4 & W5 \\
\hline Propagation direction & southeast & east & northeast & quasi-stationary & southeast \\
Horizontal wavelength $[\mathrm{km}]$ & $40-110$ & $50-120$ & $70-400$ & $70-400$ & $60-220$ \\
& $\mathbf{8 0}$ & $\mathbf{8 0}$ & $\mathbf{2 5 0}$ & $\mathbf{2 9 0}$ & $\mathbf{1 8 0}$ \\
Period & $44-110 \mathrm{~min}$ & $53-130 \mathrm{~min}$ & $1.6-24 \mathrm{~h}$ & $\gtrsim 12 \mathrm{~h}$ & $>3 \mathrm{~h}$ \\
& $\mathbf{9 0}$ min & $\mathbf{1 0 0}$ min & $\mathbf{6 h}$ & - & $\mathbf{2 4 h}$ \\
Phase speed $\left[\mathrm{m} \mathrm{s}^{-1}\right]$ & $14-19$ & $15-18$ & $4-19$ & $0-4$ & $0-9$ \\
& $\mathbf{1 7}$ & $\mathbf{1 7}$ & $\mathbf{1 3}$ & $\mathbf{0}$ & $\mathbf{2}$ \\
Vertical wavelength $[\mathrm{km}]$ & $2.9-6.9$ & $4.1-6.9$ & $2.9-9.8$ & $4.9-12$ & $5.8-14$ \\
& $\mathbf{4 . 1}$ & $\mathbf{4 . 9}$ & $\mathbf{4 . 1}$ & $\mathbf{6 . 9}$ & $\mathbf{8 . 3}$ \\
Absolute momentum flux $[\mathrm{mPa}]$ & 0.083 & 0.15 & 0.66 & 1.2 & 0.060 \\
\hline
\end{tabular}

groups. Significant wave amplitudes appear in D2 between 00:00 UTC on day 7 and 00:00 UTC on day 8 (Fig. 4b). At 00:00-12:00 UTC on day 7, PSDs with large magnitudes are distributed broadly around a strong peak at $(k, l)=$ $(0.15,0.25) \times 10^{-2}$ cycle $\mathrm{km}^{-1}$. Note that the PSD at this peak is an order of magnitude larger than the PSD peaks in Fig. 4a, implying that the amplitude of this wave group is much larger than that of the others. After 12:00 UTC on day 7 , this peak weakens, and a second peak appears at about $(k, l)=(0.4,-0.2) \times 10^{-2}$ cycle $\mathrm{km}^{-1}$. The directions of the wave vectors for the first and second peaks correspond to those for W4 and W5, respectively (Fig. 2). The other peak at around $(k, l)=(0.9,0.2) \times 10^{-2}$ cycle km$^{-1}$ is not analyzed in this study because the waves corresponding to this peak have only a small amplitude and represent neither W4 nor W5 (not shown).

The spectral domain for $\mathrm{D} 2$ is decomposed into two parts as indicated in Fig. 4b, for the $24 \mathrm{~h}$ period from 00:00 UTC on day 7. Figure $5 \mathrm{~b}$ shows the reconstructed fields of $w^{\prime}$ for the decomposed domains. The reconstructed fields capture major characteristics of W4 and W5 with an amplitude of about $94 \%$ of that of the waves in D2 revealed in Fig. 2. The horizontal wavelengths of the two are obtained from the spectra shown in Fig. 6. W4 and W5 have wavelengths of about $70-400$ and $60-220 \mathrm{~km}$, respectively, with primary peaks at 290 and $180 \mathrm{~km}$, respectively. The horizontal wavelengths of W1-W5 are summarized in Table 1 along with the other characteristics described below.

The phase velocities of the GWs at $8 \mathrm{~km}$ are obtained by calculating the PSD of $w^{\prime}$ in D1 and D2 as a function of $k, l$, and $\omega$ with the three-dimensional Fourier transform, where $\omega$ is the ground-based frequency. The PSD is then transformed into a function of $c$ and $\varphi$, where the phase speed $c=|\omega| /\left(k^{2}+l^{2}\right)^{\frac{1}{2}}$. The propagation direction $\varphi$ is determined to be $\tan ^{-1}(l / k)$ if the signs of $k$ and $\omega$ are the same or $\tan ^{-1}(l / k)+\pi$ otherwise. Figure 7 shows the PSD with respect to $c$ and $\varphi$ for $\mathrm{W} 1-\mathrm{W} 5$. W1 and W2 have similar ranges of phase speed (14-19 and $15-18 \mathrm{~m} \mathrm{~s}^{-1}$, respectively) with peaks at about $17 \mathrm{~m} \mathrm{~s}^{-1}$ for both. W3 has a broad spectrum for the phase speed and propagation direc- tion. A major portion of the PSD for W3 is located in the north-northeastward-eastward directions with phase speeds of $4-19 \mathrm{~m} \mathrm{~s}^{-1}$. In contrast to $\mathrm{W} 1-\mathrm{W} 3$, the PSD for W4 is spread over two directions, south-southwest and northnortheast, around $c=0$. The PSD at $c<4 \mathrm{~ms}^{-1}$ explains $\sim 80 \%$ of the total variance of W4 with a peak at $c=0$. That is, W4 is a quasi-stationary wave. The spectrum for W5 is also spread around $c=0$ over two directions (east-southeast and west-northwest). The peak of the PSD for W5 appears at $c \sim 2 \mathrm{~m} \mathrm{~s}^{-1}$ in the east-southeast direction.

The rightmost panels of Fig. 7 show the PSDs in D1 and $\mathrm{D} 2$, which are calculated using the whole pairs of $(k, l)$ before the decomposition into the five wave groups. Therefore, W1-W3 are represented together in the PSD for D1, and $\mathrm{W} 4$ and $\mathrm{W} 5$ are represented in the PSD for D2. The total spectrum in D1 can be explained by the sum of the PSDs for W1, W2, and W3, except in the south-southeast to south direction $\left(-90^{\circ}<\varphi<-60^{\circ}\right)$. The excepted part results from the decomposed spectra for W1-W3, which do not include PSDs around $(k, l)=(0.1,-0.3) \times 10^{-2}$ cycle km ${ }^{-1}$ (Fig. 4a). The total spectrum in D1 has a continuous, single structure: the major portion of the PSD is distributed following an arc that passes the origin and $(c, \varphi)=\left(17 \mathrm{~m} \mathrm{~s}^{-1}, 0\right)$. The PSD is also bounded by two circles of which one passes $(c, \varphi) \sim\left(24 \mathrm{~m} \mathrm{~s}^{-1}, 0\right)$ and the origin and the other passes $(c, \varphi) \sim\left(10 \mathrm{~m} \mathrm{~s}^{-1}, 0\right)$ and the origin.

Using simple geometry, one can show that if a reference frame moving with a certain velocity $\boldsymbol{c}_{\mathrm{r}}$ is defined, the isoline of the phase speed relative to the reference frame $\widetilde{c}=$ $c-\boldsymbol{c}_{\mathrm{r}} \cdot(\cos \varphi, \sin \varphi)$ is shaped like a circle passing the origin in the $c-\varphi$ domain. The isoline of $\widetilde{c}=0$ is shaped into a perfect circle that passes the origin and $(c, \varphi)=\left(\left|\boldsymbol{c}_{\mathrm{r}}\right|, \varphi_{\mathrm{r}}\right)$, where $\varphi_{\mathrm{r}}$ is the direction of $\boldsymbol{c}_{\mathrm{r}}$. If we set $\boldsymbol{c}_{\mathrm{r}}=\boldsymbol{U}$, where $\boldsymbol{U}$ is the background horizontal wind, $\widetilde{c}$ becomes the intrinsic phase speed $\hat{c}$. Note that, for hydrostatic waves, the isoline of $\hat{c}$ corresponds to an isoline of the vertical wavenumber $m$ for a given background state, as $m^{2}=N^{2} / \hat{c}^{2}$ when the medium-frequency approximation is applied (Fritts and Alexander, 2003). These facts suggest three possible mech- 
(a)

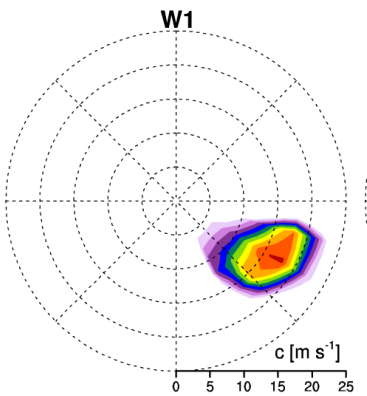

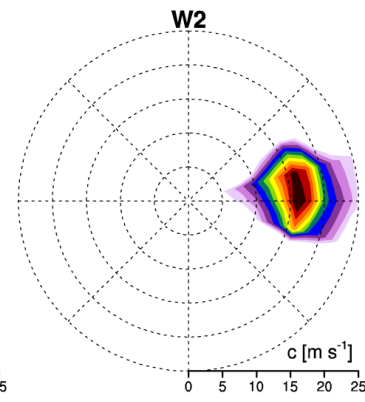

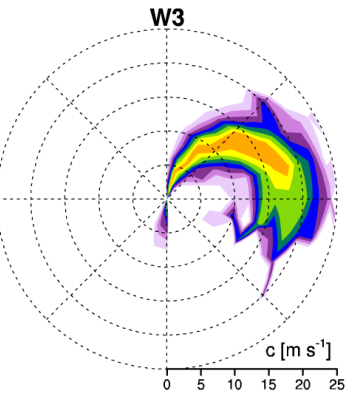

(b)

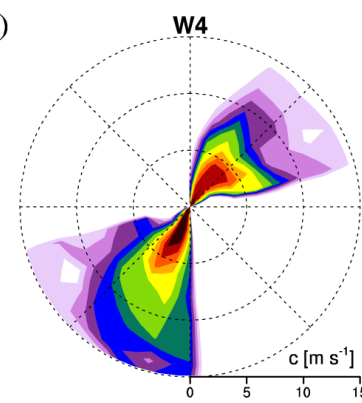

W5

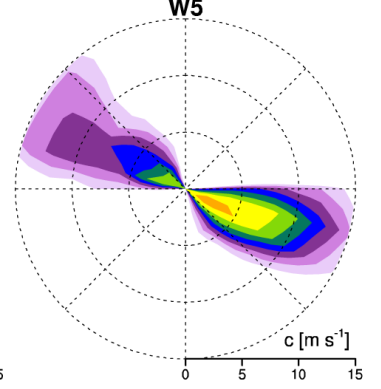

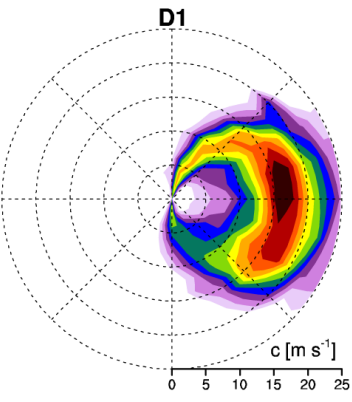

D2
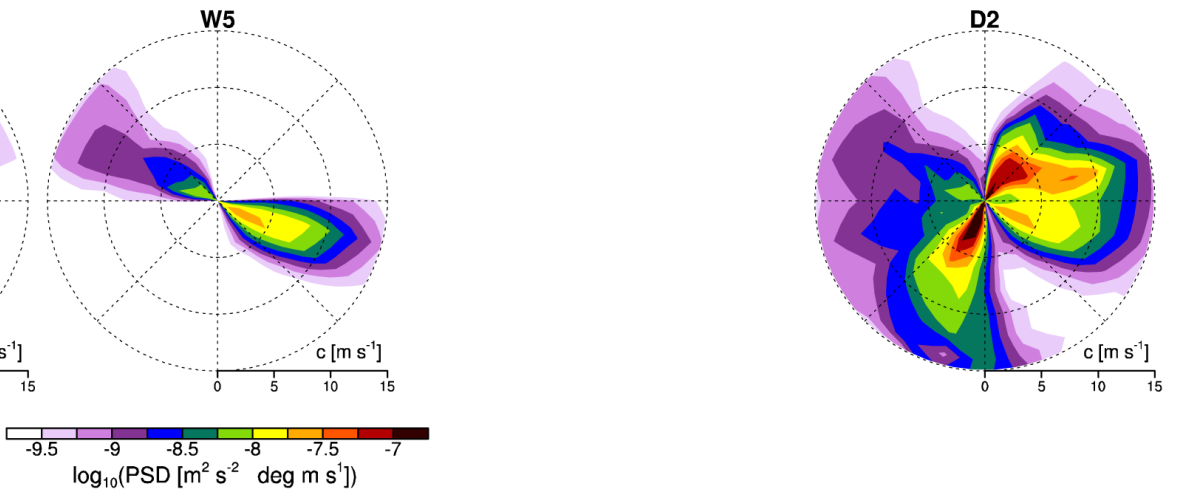

Figure 7. Power spectra of $w^{\prime}$ at $z=8 \mathrm{~km}$ as a function of phase speed and propagation direction calculated in (a) $48-73^{\circ} \mathrm{N}, 20-60^{\circ} \mathrm{E}$ and (b) $21-46^{\circ} \mathrm{N}, 20-60^{\circ} \mathrm{E}$. The rightmost panels were obtained using all pairs of $(k, l)$, and the other panels are for W1, W2, and W3 in (a) and for $\mathrm{W} 4$ and $\mathrm{W} 5$ in (b).

anisms by which the total spectrum in D1 can be made into the arc shape shown in Fig. 7a.

The first is the generation of waves whose phases are locked to the wave source moving eastward at a certain speed $c_{\mathrm{S}}$ (i.e., moving obstacle effect). That is, the phase speed relative to the moving source is 0 . If we set the reference frame following the moving source, $\boldsymbol{c}_{\mathrm{r}}=\left(c_{\mathrm{s}}, 0\right)$, then the spectral peak would appear where $\widetilde{c}=0$, i.e., on the circle passing $(c, \varphi)=\left(c_{\mathrm{s}}, 0\right)$ and the origin for the $c-\varphi$ spectrum. If this is the case, $c_{\mathrm{s}}$ should be approximately $17 \mathrm{~m} \mathrm{~s}^{-1}$, considering the peak in the spectrum in D1 (Fig. 7a).

The second possibility is the resonance of waves to a vertical structure of the flow. If the GWs in D1 are generated resonantly to a certain vertical scale that the GW source would have, the generated waves can have a strong spectral peak at the corresponding vertical wavenumber $m$, and thus $\hat{c}(= \pm|N / m|)$ (e.g., Song and Chun, 2005). In this case, the spectrum in the $c-\varphi$ domain at the generation altitude would have an arc shape. Then, if the waves do not undergo significant filtering during their propagation from the generation altitude to $z=8 \mathrm{~km}$, the arc-shaped spectrum would be preserved at $8 \mathrm{~km}$. If this is the case, the direction of $\boldsymbol{c}_{\mathrm{r}}=\boldsymbol{U}$ should be almost zonal and eastward at the generation altitude for all of W1-W3, considering the spectral shape in D1 (Fig. 7a).

The third possible case is when a considerable amount of critical-level filtering occurs by the background flow, where $\hat{c} \sim 0$. If the GWs in D1 are strongly filtered by background westerlies with wind speeds of $\gtrsim 24 \mathrm{~m} \mathrm{~s}^{-1}$ and $\lesssim 10 \mathrm{~m} \mathrm{~s}^{-1}$, only the waves with $10 \cos \varphi<c<24 \cos \varphi \mathrm{ms}^{-1}$ can remain, and the spectrum would be bounded sharply, as shown in Fig. 7a. The validity of these three possibilities for our case can be probed by using information such as the level of gravity-wave generation, vertical structures of the waves and background flow, and/or moving speed of candidate sources of GWs. This is discussed in Sect. 4.

The total spectrum in $\mathrm{D} 2$ can also be explained by the sum of the PSDs for W4 and W5, except at $0<\varphi<15^{\circ}$. The excepted part results from the spectral components $(k, l) \sim$ $(0.9,0.25) \times 10^{-2}$ cycle km${ }^{-1}$ that are not included into the decomposed spectra for both W4 and W5 (Fig. 4b). In contrast to the total spectrum in D1, that in D2 is not shaped into an arc structure with a constant $\tilde{c}$ and is not sharply bounded by some ranges of $(c, \varphi)$. Rather, it can be characterized by the dominance of very low phase-speed components. One feasible explanation for this may be the generation of waves by a quasi-stationary source (obstacle effect). The possible source is further discussed in Sect. 4.

The periods of W1-W5 can be obtained by integrating the $\operatorname{PSD}(k, l, \omega)$ with respect to $k$ and $l$ for each decomposed spectrum. Figure 8 shows the (ground-based) frequency spectra of $w^{\prime}$ at $8 \mathrm{~km}$. Here, the positive and negative frequencies indicate eastward $\left(-90^{\circ}<\varphi \leq 90^{\circ}\right)$ and westward $\left(90^{\circ}<\varphi \leq 270^{\circ}\right)$ propagation directions, respectively. 


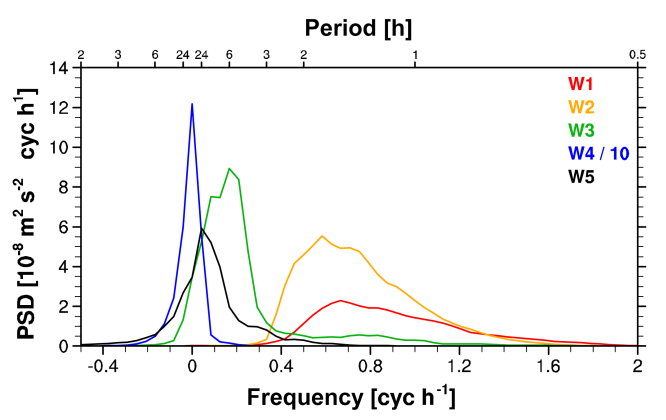

Figure 8. Frequency power spectra of $w^{\prime}$ at $z=8 \mathrm{~km}$ for $\mathrm{W} 1$ (red), W2 (yellow), W3 (green), W4 (blue), and W5 (black). The positive and negative frequencies indicate eastward and westward propagation of the waves, respectively. For W4, the power spectrum is divided by 10 .

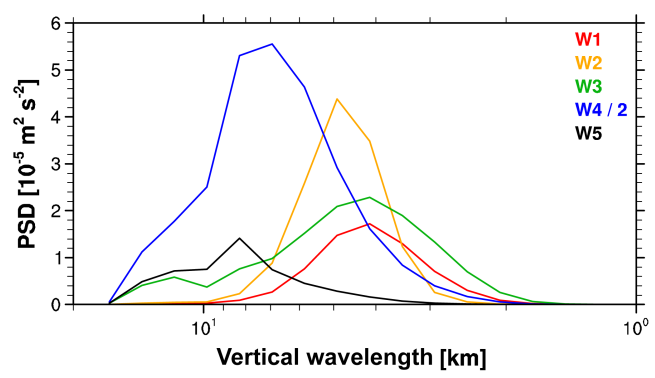

Figure 9. The same as in Fig. 6 except for the vertical-wavelength power spectra of $w^{\prime}$ at $z=8 \mathrm{~km}$.

$\mathrm{W} 1$ and $\mathrm{W} 2$ have periods of about $44-110$ and 53-130 min, respectively. The period of W3 (1.6-24h) is much longer than that of $\mathrm{W} 1$ and $\mathrm{W} 2$; there is a spectral gap between $\mathrm{W} 3$ and $\mathrm{W} 1 / \mathrm{W} 2$ at about $3 \mathrm{~h}$. As noted above, W4 is quasistationary $(\omega \sim 0)$. W5 has long periods with a peak at $24 \mathrm{~h}$.

The vertical wavelength spectra for W1-W5 at $8 \mathrm{~km}$ are obtained by wavelet analysis. The Morlet wavelet transform is performed for vertical profiles of the reconstructed $w^{\prime}$ multiplied by $\exp (-z / 2 H)$ in D1 and D2 during the selected $24 \mathrm{~h}$ periods shown in Fig. 4a and b, respectively, where the scale height $H=7 \mathrm{~km}$. The resulting wavelength spectra at $z=8 \mathrm{~km}$ are averaged horizontally and temporally and shown in Fig. 9. W1 and W3 have wavelengths of about 37 and $3-10 \mathrm{~km}$, respectively, with peaks at $4 \mathrm{~km}$ for both. W2 has wavelengths of $4-7 \mathrm{~km}$ with a peak at $5 \mathrm{~km}$. W4 and W5 have generally larger vertical wavelengths than W1W3. Their wavelength ranges are 5-12 and 6-14 km, respectively, with peaks at 7 and $8 \mathrm{~km}$, respectively. Note that, for this wavelet result at $z=8 \mathrm{~km}$, the spectrum at vertical wavelengths larger than $\sim 8 \mathrm{~km}$ would contain uncertainty (Torrence and Compo, 1995). However, even though the uncertainty at these wavelengths is considered, the peak wavelengths for W4 and W5 do not become less than $7 \mathrm{~km}$ (Fig. 9). The vertical wavelengths simulated in our case are generally greater than those in the previous modeling studies
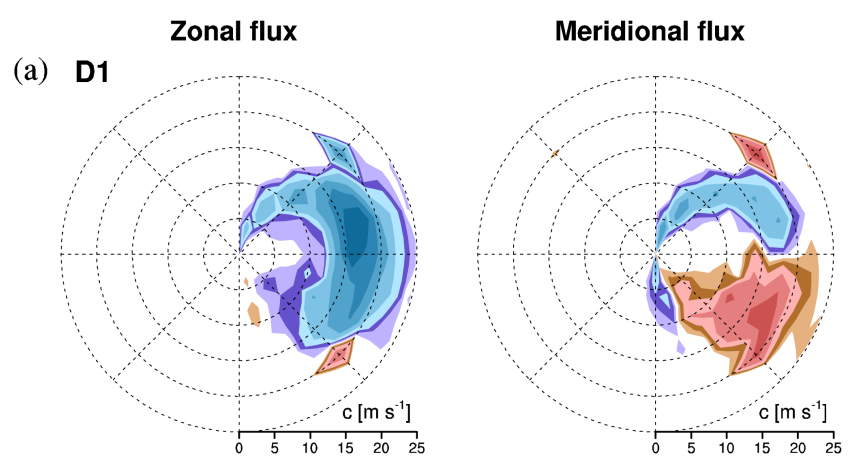

(b)

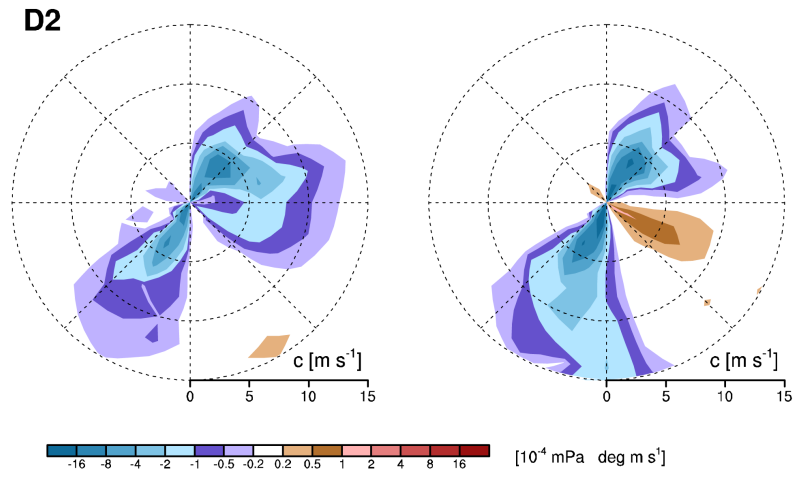

Figure 10. (left) Zonal and (right) meridional momentum flux spectra at $z=8 \mathrm{~km}$ as a function of phase speed and propagation direction calculated in (a) $48-73^{\circ} \mathrm{N}, 20-60^{\circ} \mathrm{E}$ and (b) $21-46^{\circ} \mathrm{N}, 20-$ $60^{\circ} \mathrm{E}$.

(e.g., Zhang, 2004, and PS07). Possible reasons for this may include the difference in the baroclinic wave structure and evolution in the studies, which may affect both the structure of the wave sources and the background flow. Note that the baroclinic wave in our simulation has large amplitudes near the ground, while the previous modeling studies have emphasized baroclinic waves in the upper troposphere (cf. cyclonic and anticyclonic life-cycle simulations in PS07). The differing analysis method between the studies could also be responsible for the difference in the results.

Figure 10 shows the phase-velocity spectra of the vertical flux of horizontal momentum for the waves $\left(\rho_{0} \overline{u^{\prime} w^{\prime}}\right.$ and $\rho_{0} \overline{v^{\prime} w^{\prime}}$, where $\rho_{0}$ is the mean density, and $u^{\prime}$ and $v^{\prime}$ are the zonal and meridional-velocity perturbations, respectively) in D1 and D2 at $8 \mathrm{~km}$. The spectral shapes of the momentum flux in D1 and D2 are generally similar to those of $w^{\prime}$ (Fig. 7). The zonal momentum flux in D1 is dominantly negative, and the meridional momentum flux is negative and positive for the waves propagating northeastward and southeastward, respectively. That is, the direction of the horizontal momentum in D1 is opposite to and the same as that of the ground-based phase velocity if the momentum is transported upward and downward, respectively. Given that the background wind for $\mathrm{W} 1, \mathrm{~W} 2$, and $\mathrm{W} 3$ at $8 \mathrm{~km}$ is westerly at speeds higher than $\sim 20 \mathrm{~m} \mathrm{~s}^{-1}$ (Fig. 1), the direction of the wave propagation relative to the background flow (i.e., direction of the intrinsic 
(a) Day 7, 00:00

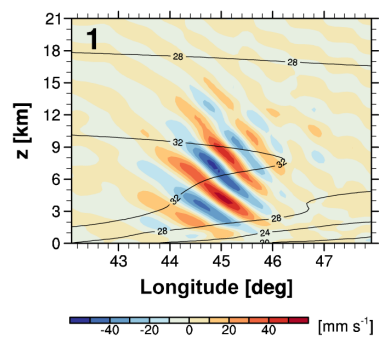

(b) Day 7, 12:00

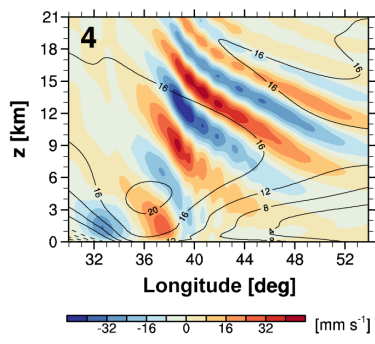

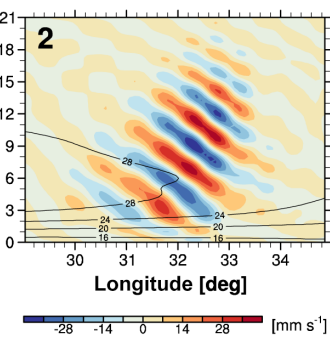
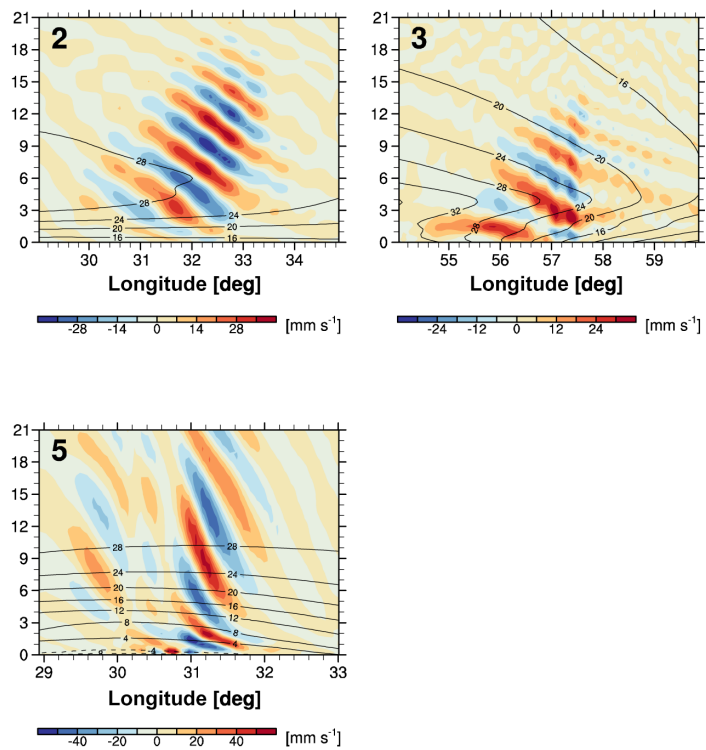

Figure 11. Vertical cross sections of the reconstructed $w^{\prime}$ (shading) along the axes indicated by green lines in Fig. 5. The background wind projected onto the propagation direction of each wave is also plotted (contour). $w^{\prime}$ is multiplied by $\exp (-z / 2 H)$, where $H=7 \mathrm{~km}$.

phase velocity) is opposite to that of the ground-based phase velocity. In theory, the direction of the horizontal momentum transported by GWs is the same as that of the intrinsic phase velocity. Therefore, the signs of the zonal and meridional momentum fluxes shown in Fig. 10a consistently imply the upward transport of momentum by the waves in D1. The signs of the momentum flux in D2 also imply the upward transport of momentum by the waves. Considering that the background westerly is stronger than $15 \mathrm{~m} \mathrm{~s}^{-1}$, the directions of the intrinsic phase velocity of W4 and W5 are southwest and northwest, respectively. They are the same as the directions of the horizontal momentum transported by W4 and W5 when the flux is upward (Fig. 10b). This result indicates that the sources of W1-W5 exist below $8 \mathrm{~km}$.

The absolute horizontal momentum flux $\left(\rho_{0}\left[{\overline{u^{\prime} w^{\prime}}}^{2}+\right.\right.$ $\left.\overline{v^{\prime} w^{\prime}}\right]^{\frac{1}{2}}$ ) for $\mathrm{W} 1-\mathrm{W} 5$ is presented in Table 1 . This is calculated by integrating the phase-velocity spectra of the momentum flux for each wave group (not shown) with respect to $c$ and $\varphi$. The momentum flux values in Table 1 can be interpreted as averages over the whole area of D1 or D2 (25 latitudes $\times 40^{\circ}$ longitudes) during the $24 \mathrm{~h}$ when the spectra are calculated. The momentum flux for $\mathrm{W} 4(1.2 \mathrm{mPa})$ is the largest (Table 1) because its amplitudes are much larger than those of the others (Fig. 4). Given that the momentum flux launched by GW parameterizations in climate models is typically about $1-3 \mathrm{mPa}$ for one azimuthal direction of propagation (e.g., Geller et al., 2013), the averaged amount of momentum transported by W4 is considerable. Note that the momentum flux parameterized by the frontal GW scheme used in Richter et al. (2010) was about $0.4-2.8 \mathrm{mPa}$ at $100 \mathrm{hPa}$ in the midlatitudes and high latitudes (see their Fig. 3). The averaged momentum fluxes for $\mathrm{W} 1, \mathrm{~W} 2$, and $\mathrm{W} 5$ are small (Table 1), although these waves have significant momentum fluxes locally (not shown).

\subsection{Vertical propagation of GWs}

Figure 11 shows the vertical cross sections of the reconstructed $w^{\prime}$ for W1-W5 along the axes indicated in Fig. 5 (green lines), superimposed on the speed of the background wind projected onto the propagation direction of each wave (i.e., $|\boldsymbol{U} \cdot(\cos \varphi, \sin \varphi)|)$. The position and angle of the axes are determined so that the cross sections capture the perturbations at the highest altitude possible and, at the same time, at the lower troposphere. Consistent with the previous discussion (Fig. 10), the cross sections of W1-W3 exhibit the structures of waves propagating upward: the phase lines of the waves with westward intrinsic phase velocities tilt upwind. During the upward propagation, W1, W2, and W3 are significantly damped around $z \sim 11,14$, and $9 \mathrm{~km}$, respectively. For $\mathrm{W} 1$ and $\mathrm{W} 2$, the background wind around $z \sim 11$ and $14 \mathrm{~km}$, respectively, does not significantly change in the vertical direction. Thus, the projected background-wind speed does not become close to the phase speed of the waves $\left(\lesssim 24 \mathrm{~m} \mathrm{~s}^{-1}\right.$, Fig. 7a) in the upper troposphere and above (Fig. 11a). This confirms that W1 and W2 do not undergo the critical-level filtering process. Rather, it is feasible that they are damped by the numerical diffusion of the model. Note that the peak value of the horizontal wavelengths for W1 and W2 $(80 \mathrm{~km})$ corresponds to $\sim 8 \Delta_{\mathrm{h}}$ and that of the vertical wavelengths (4-5 km) to $\sim 7 \Delta_{z}$ in the upper troposphere, where $\Delta_{\mathrm{h}}$ and 
$\Delta_{z}$ are the horizontal and vertical grid spacings, respectively. The waves with scales smaller than these peak values may undergo significant implicit diffusion, provided that the effective resolution of numerical models is typically considered as $\sim 6 \Delta_{\mathrm{h}}$ (e.g., Skamarock et al., 2014). The stronger damping of W1 compared to W2, as shown in Fig. 11a, is also suggestive of numerical diffusion, which is more effective for horizontally and vertically smaller-scale waves than for larger waves (Figs. 6 and 9).

The damping of W3 is attributed to both numerical diffusion and critical-level filtering. The background wind for W3 changes significantly in the vertical and horizontal directions (Fig. 11a). This horizontal and vertical wind shear results from the formation of the strong low-level jet southwest of the cross-section domain (see Fig. 1). From about $9 \mathrm{~km}$, the projected background-wind speed becomes less than $20 \mathrm{~m} \mathrm{~s}^{-1}$ at $57.4^{\circ} \mathrm{E}$. It may have filtered some portion of W3 with the phase speed of $\lesssim 20 \mathrm{~m} \mathrm{~s}^{-1}$ (Fig. 7a) above $z \sim 9 \mathrm{~km}$.

W4 and W5 propagate to higher altitudes with less damping than W1-W3 (Fig. 11b). Less damping may have resulted from the larger vertical and/or horizontal scales of W4 and W5 compared to W1-W3 (Figs. 6 and 9). In addition, W4 and W5 tilt vertically with much smaller zenith angles than W1-W3, which can be found in the vertical cross sections perpendicular to the wave vectors (not shown). A small zenith angle implies high intrinsic frequency and vertical group velocity (Holton, 1992). Thus, W4 and W5 propagate upward faster and undergo diffusion for shorter durations than W1-W3. They do not undergo critical-level filtering during the upward propagation because their phase speed is much less than the background-wind speed (Fig. 7b).

In Fig. 11, a node structure appears in the wave perturbation, particularly for W3 and W4. A node structure can appear when two or more packets of waves are colocated. W3 and W4 are not (quasi-)monochromatic waves. The $k-l$ spectrum in D2 at 12:00-24:00 UTC on day 7 (Fig. 4b) has two distinct peaks for W4 at $l \sim 0.2$ and $0.7 \times 10^{-2}$ cycle km$^{-1}$, which indicate the two wave packets. The spectrum in D1 at 00:00-12:00 UTC on day 7 (Fig. 4a) has several peaks for $\mathrm{W} 3$ at $(k, l) \sim(0.3,0),(0.1,0.45)$, $(0.6,0.5) \times 10^{-2}$ cycle km${ }^{-1}$, etc. The node structure can also be partly attributed to the partial reflection of waves. A partial reflection occurs where the wind or stability of the background flow changes significantly, and it causes interference between the primary wave and reflected wave in perturbation fields (e.g., Gossard and Hooke, 1975; Kim et al., 2012). The background wind for $\mathrm{W} 3$ has a large gradient in the vertical and horizontal directions in the lower and middle troposphere (Fig. 11a), which can possibly induce the partial reflection. In fact, in the horizontal-wavelength spectrum with respect to the height (not shown), we confirmed that the horizontal wavelength of W3 decreases continuously with height; this suggests the possibility of partial reflection. The possibility and details of the partial reflection associated with the baro- clinic jet merit further study in the future, provided that the reflection can affect the amount of momentum transported into the upper levels.

It is noteworthy that the initial setting for the background flow used in this experiment (JW06) is focused on the troposphere. The background wind in the stratosphere here differs from that in the real atmosphere. In this experiment, the upper tropospheric midlatitude jet, for which the core is at $z \sim 11 \mathrm{~km}$ with a speed of $35 \mathrm{~m} \mathrm{~s}^{-1}$ (refer to Fig. 2 in Park et al., 2013), does not decelerate enough above the jet core. Thus, the background-wind speed reaches $\sim 30 \mathrm{~m} \mathrm{~s}^{-1}$ at the model lid $(z \sim 31 \mathrm{~km})$ (Fig. 1a in JW06). This makes further investigation of the wave propagation into the stratosphere from the simulation results invalid. Moreover, the numerical damping mentioned above suppresses the wave propagation into the stratosphere. However, the spectral analysis of the phase velocities for the simulated waves gives some insights to the stratospheric propagation. The phase speeds of $\mathrm{W} 1-$ W3 range from $10 \cos \varphi$ to $24 \cos \varphi \mathrm{ms}^{-1}$ (Fig. 7a). If the background westerly decelerates to $U_{0}$, the waves with phase speeds higher than $U_{0} \cos \varphi$ must be filtered at their critical levels. In the midlatitudes, the westerly typically decelerates to about $10 \mathrm{~m} \mathrm{~s}^{-1}$ or lower above the jet. Thus, it is hard for the waves to propagate upward. Only in case when the midlatitude tropospheric jet and stratospheric winter jet are connected at the northern edge of the midlatitude jet can the wind speed there be higher than $\sim 10 \mathrm{~m} \mathrm{~s}^{-1}$, and some portion of the waves has the potential to propagate there. However, W4 and W5 have very low phase speeds with peaks at 0 and $2 \mathrm{~ms}^{-1}$, respectively (Fig. 7b). They could propagate into the stratosphere in the wintertime. In the summertime, when the stratospheric wind is easterly, all of W1-W5 must be filtered by the easterly.

\section{Discussion on the GW generation}

It was shown in Fig. 11 that the perturbations for the upward propagating waves are observed throughout the troposphere, which suggests that the wave sources are in the lower troposphere. In this section, the perturbations in the lower troposphere are investigated, and the generation of the waves is discussed.

Figure 12a shows $w^{\prime}$ at selected levels from $z=250 \mathrm{~m}$ to $5 \mathrm{~km}$ at 12:00 UTC on day 6 and at 06:00 UTC on day 7, superimposed on the (total) potential temperature at $z=250 \mathrm{~m}$ (green). The $w^{\prime}$ field at 12:00 UTC on day 6 exhibits commashaped disturbances at $250 \mathrm{~m}$ around the high-latitude warm core. The alignment of these disturbances is almost parallel to the $250 \mathrm{~m}$ isentropic lines around the warm core, except at $\sim 66^{\circ} \mathrm{N}, 18^{\circ} \mathrm{E}$. The tail of the comma-shaped disturbances is aligned to follow the occluded front where the warm and cold fronts meet. The disturbances have a broad horizontalwavelength spectrum ranging from about 50 to $1000 \mathrm{~km}$, with a dominance at $300-500 \mathrm{~km}$ (not shown). The magni- 

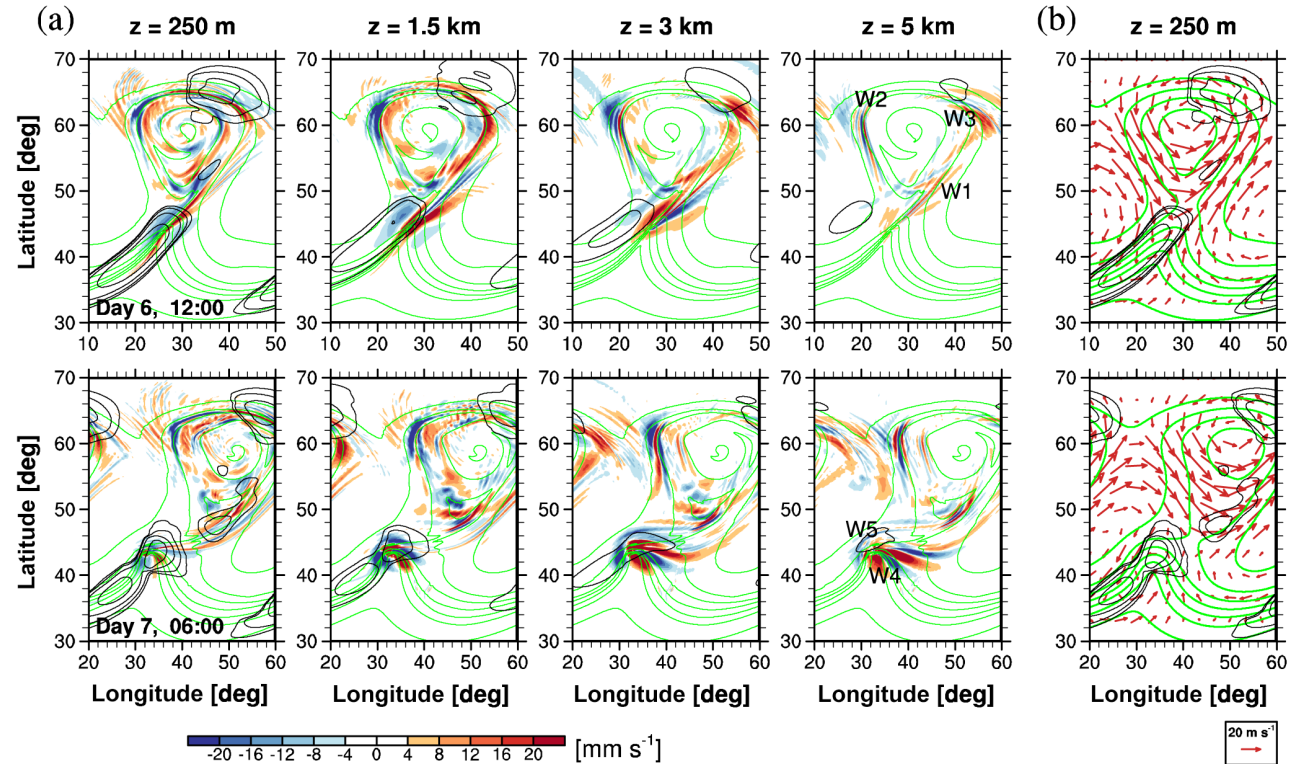

Figure 12. (a) $w^{\prime}$ (shading) and frontogenesis function (FF, black) at $z=0.25,1.5,3$, and $5 \mathrm{~km}$ (from left to right) superimposed on the $250 \mathrm{~m}$ total potential temperature (green) and (b) $250 \mathrm{~m}$ background potential temperature (green) and horizontal wind (arrow) along with FF (black) at (upper) 12:00 UTC on day 6 and (lower) 06:00 UTC on day 7. $w^{\prime}$ is multiplied by $\exp (-z / 2 H)$. FF is plotted at values of 0.1 , $0.3,1,3$, and $10 \mathrm{~K}^{2}(100 \mathrm{~km})^{-2} \mathrm{~h}^{-1}$. The contour intervals for potential temperature and pressure are $8 \mathrm{~K}$ and $8 \mathrm{hPa}$, respectively.

tude of $w^{\prime}$ is largest at about $z=1.5 \mathrm{~km}$. At this level, it is clearly seen that the larger-scale disturbances (with wavelengths of several hundred kilometers) dominate the $w^{\prime}$ field and that the smaller-scale disturbances (with wavelengths of $\sim 100 \mathrm{~km}$ ) are superimposed on the larger-scale disturbances (Fig. 12a). The amplitude of the larger-scale disturbances above $z \sim 1.5 \mathrm{~km}$ decreases with height, and they disappear above $z \sim 4 \mathrm{~km}$, except at around $61^{\circ} \mathrm{N}, 46^{\circ} \mathrm{E}$. However, the smaller-scale disturbances reach $z=5 \mathrm{~km}$ (Fig. 12a) and further above this height.

The disturbances at $z=5 \mathrm{~km}$ closely resemble those at $z=8 \mathrm{~km}$, as shown in Fig. 2. This confirms that the smallerscale disturbances above the occluded front and at the western part of the $250 \mathrm{~m}$ warm core are $\mathrm{W} 1$ and $\mathrm{W} 2$, respectively. The larger-scale disturbances northeast of the warm core at $5 \mathrm{~km}$ are W3. In addition, the wave packet of W3 that is aligned with the isentropic lines at $250 \mathrm{~m}$ is advected eastward in the lower troposphere (Fig. 12a). This explains why $\mathrm{W} 3$ at $8 \mathrm{~km}$ is not aligned with the $250 \mathrm{~m}$ isentropic lines, as discussed previously in Sect. 3.2 (Fig. 2). The large-scale disturbances disappearing at $z \lesssim 4 \mathrm{~km}$ could not be confirmed to be gravity waves which must have absolute intrinsic frequencies $(|\hat{\omega}|)$ that are larger than $|f|$. This is because the spectral range of $|\hat{\omega}|$ that we estimated using the Fourier transform (not shown) included $f$ in this layer. This implies that some of them are GWs undergoing critical-level filtering during the propagation in this layer $(|\hat{\omega}|=f)$, and the others are non-GWs.
At 06:00 UTC on day 7, a large magnitude of $w^{\prime}$ appears at $z=1.5 \mathrm{~km}$ at $44^{\circ} \mathrm{N}, 33^{\circ} \mathrm{E}$, where the midlatitude low and associated fronts are isolated from the higher-latitude trough (Fig. 12a). The perturbations have horizontal scales of approximately $50-500 \mathrm{~km}$ and tend to align with the $250 \mathrm{~m}$ isentropic lines. The perturbations propagate upward to $z=$ $5 \mathrm{~km}$ and further, and they disperse eastward during the upward propagation without significant changes in the horizontal scale. Comparing $w^{\prime}$ at 5 and $8 \mathrm{~km}$ (Fig. 2) confirms that the perturbations aligned in the east-southeast direction eastward of $\sim 33^{\circ} \mathrm{E}$ are $\mathrm{W} 4$ and those at the northwest of the cold front are W5.

The disturbances at $z=1.5 \mathrm{~km}$ around the high-latitude warm core at 12:00 UTC on day 6 (Fig. 12a) resemble the gravity waves above the occluded surface front in the simulation of the cyclonic baroclinic life cycle by PS07 (see their Fig. 8). Note that, in our simulation, the occluded front intrudes into the warm core. In addition, the structure of W5 is similar to that of the frontal gravity waves simulated in the anticyclonic baroclinic life cycle by PS07 (see their Fig. 10) in terms of the alignment of the phase line and location near the cold front. This is seen more clearly at $8 \mathrm{~km}$, as shown in Fig. 2. Therefore, it can be suggested that the GWs in our simulation are generated by the surface front. Previous studies showed that, when the surface front is developed with a sufficiently small cross-frontal scale, GWs can be emitted above the front and are stationary with respect to the front (e.g., Snyder et al., 1993; Shakespeare, 2015). 
(a)

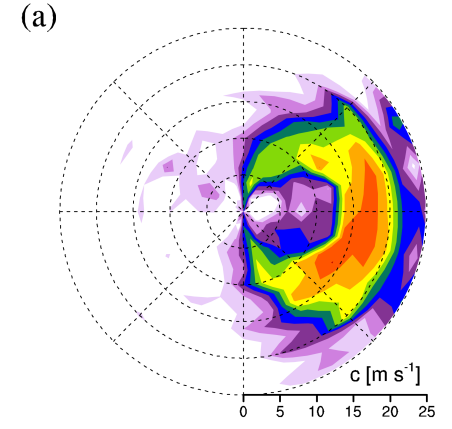

(b)

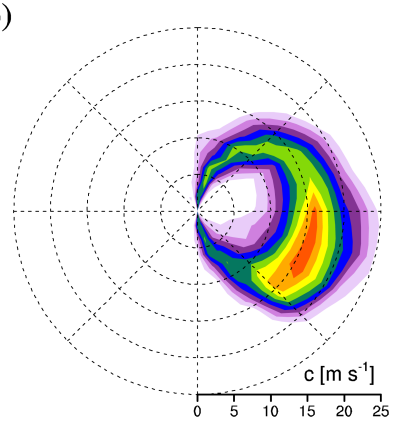

(c)
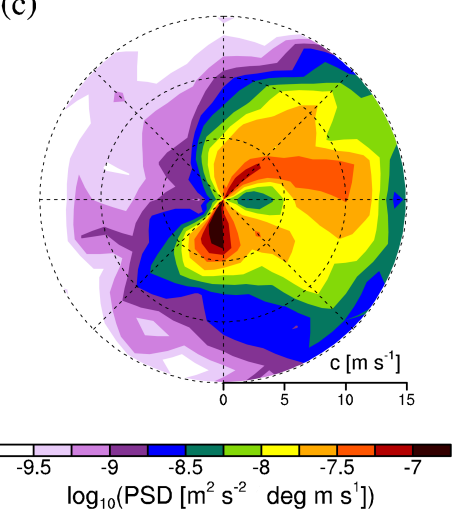

Figure 13. Power spectra of $w^{\prime}$ at $z=1.5 \mathrm{~km}$ as a function of phase speed and propagation direction calculated in (a, b) $48-73^{\circ} \mathrm{N}, 20$ $60^{\circ} \mathrm{E}$ and (c) $21-46^{\circ} \mathrm{N}, 20-60^{\circ} \mathrm{E}$. In (a) and (b), the spectra were obtained for the wave components with horizontal wavelengths larger and smaller than $150 \mathrm{~km}$, respectively.

In order to compare the phase speeds of the waves generated in the lower troposphere to the moving speeds of the frontal system, the phase-velocity power spectra of $w^{\prime}$ at $z=1.5 \mathrm{~km}$ are calculated in D1 and D2 (Fig. 13). In D1, the spectra are obtained separately for the larger-scale and smaller-scale perturbations by filtering $w^{\prime}$ at the horizontal wavelength of $150 \mathrm{~km}$. The spectra for the larger- and smaller-scale perturbations have a similarity (Fig. 13a and b): they are arc shaped and have a peak at $\sim 16 \mathrm{~m} \mathrm{~s}^{-1}$ in the eastsoutheastern direction, although the spectrum for the largerscale perturbations is noisy and seems broader. This implies that the phase speed of the perturbations generated in D1 does not significantly depend on their horizontal scale. Based on the analysis of the phase-velocity spectrum in Sect. 3.2, the arc passing $\left(16 \mathrm{~m} \mathrm{~s}^{-1}, 0\right)$ in the $c-\varphi$ spectrum would be the isoline of the zero phase speed relative to a reference frame moving at $16 \mathrm{~m} \mathrm{~s}^{-1}$. Given that the high-latitude warm core and associated occluded front move eastward at a speed of $16.0-17.4 \mathrm{~m} \mathrm{~s}^{-1}$ following the baroclinic-wave trough (Fig. 2), the perturbations in D1 are quasi-stationary relative to the warm core. The perturbations in D2 are quasistationary with respect to the ground (Fig. 13c), and the location where the midlatitude warm and cold fronts meet is almost fixed $\left(\sim 44^{\circ} \mathrm{N}, 33^{\circ} \mathrm{E}\right)$ between 00:00 and 12:00 UTC on day 7 (Fig. 2). Based on these results, the GWs in D1 and D2 are concluded to be generated by the surface fronts.

In Sect. 3.2, three possible mechanisms for the spectral shapes of W1-W3 in the upper troposphere (Fig. 7) were suggested: the generation of waves whose phase is locked to a source moving eastward at $\sim 17 \mathrm{~m} \mathrm{~s}^{-1}$, resonance of waves to a vertical structure of the flow, and a large amount of critical-level filtering. As discussed in this section, we already found that the first is the responsible mechanism associated with the surface fronts. Nonetheless, the possibility of the others is worth assessing. If $\mathrm{W} 1-\mathrm{W} 3$ were generated resonantly with the vertical scale of the frontal system, the background-wind direction near the surface should be almost zonal for all of W1-W3 (Sect. 3.2). However, this was not true. The critical-level filtering does not seem significant in the middle troposphere (Fig. 11a). In addition, the phase-velocity spectra at $8 \mathrm{~km}$ are generally similar to those at $1.5 \mathrm{~km}$, although there is a slight shift in the phase direction for the spectral peak in D1 from about -15 to $+10^{\circ}$ (Fig. 13). This also confirms that the critical-level filtering in the middle troposphere does not significantly affect the spectrum of the waves.

For the purpose of GW parameterization, it is required to predict the occurrence of subgrid-scale GWs using grid-scale variables. The parameterization of frontal GWs was first attempted by Charron and Manzini (2002); their work has been used in the Whole Atmosphere Community Climate Model (WACCM) (Richter et al., 2010). In this parameterization, a certain threshold value of the frontogenesis function (FF) (Miller, 1948; Hoskins, 1982) defined by

$$
\begin{aligned}
\mathrm{FF} \equiv & \frac{1}{2} \frac{\mathrm{D}}{\mathrm{D} t}|\nabla \theta|^{2} \\
= & -\left(\frac{1}{a \cos \phi} \frac{\partial \theta}{\partial \lambda}\right)^{2}\left(\frac{1}{a \cos \phi} \frac{\partial u}{\partial \lambda}-\frac{v \tan \phi}{a}\right) \\
& -\left(\frac{1}{a} \frac{\partial \theta}{\partial \phi}\right)^{2} \frac{1}{a} \frac{\partial v}{\partial \phi}-\frac{1}{a^{2} \cos \phi} \frac{\partial \theta}{\partial \lambda} \frac{\partial \theta}{\partial \phi} \\
& \left(\frac{1}{a \cos \phi} \frac{\partial v}{\partial \lambda}+\frac{1}{a} \frac{\partial u}{\partial \phi}+\frac{u \tan \phi}{a}\right)
\end{aligned}
$$

is used to diagnose the GW occurrence in each model grid point, where $\theta, \lambda, \phi$, and $a$ are the potential temperature, longitude, latitude, and mean radius of the Earth, respectively. Therefore, it might be important to assess the ability of the 
FF diagnostic as an indicator of GW generation in order to further improve the frontal GW parameterization.

FF in the lower troposphere is shown in Fig. 12a (black). Here, FF is calculated using the background fields of the potential temperature and horizontal wind which are also shown in Fig. $12 \mathrm{~b}$ at $z=250 \mathrm{~m}$. At 12:00 UTC on day 6 , FF at $250 \mathrm{~m}$ exhibits large values at two regions: along the cold front due to the strong deformation of the northerly flow and northeast of the high-latitude warm core due to the convergence of the southerly flow (Fig. 12b). At this time, W1 is connected to the northern region of the large FF along the cold front at $250 \mathrm{~m}\left(\sim 45^{\circ} \mathrm{N}\right)$, and it seems to stretch northeastward following the strong southwesterly. W3 at $250 \mathrm{~m}$ and $1.5 \mathrm{~km}$ is located in the large FF region at $250 \mathrm{~m}$ northeast of the warm core. However, there is no indication of W2 by the FF field. In fact, FF is largely negative in the region of W2 owing to the divergence of the northerly flow (Fig. 12b). The negative FF implies that the (background) potential-temperature gradient weakens following the flow, as $\mathrm{FF}=\frac{1}{2} \frac{\mathrm{D}}{\mathrm{D} t}|\nabla \theta|^{2}$ (Eq. 1). Note that, although the change in $|\nabla \theta|$ is negative following the northerly in the $\mathrm{W} 2$ region (Fig. $12 \mathrm{~b}$ ), $|\nabla \theta|$ itself is still large there, which may have caused the excitation of W2. At 06:00 UTC on day 7, when the midlatitude low and fronts are isolated, the $250 \mathrm{~m} \mathrm{FF}$ at the cold front has two local peaks (Fig. 12). W4 and W5 are developed at $1.5 \mathrm{~km}$ in the region of the northern peak of $250 \mathrm{~m} \mathrm{FF}$, whereas the southern peak seems not linked with any GW perturbations. There is also a significant $\mathrm{FF}$ signal at $48^{\circ} \mathrm{N}, 47^{\circ} \mathrm{E}$ at $250 \mathrm{~m}$, where $\mathrm{W} 1$ is located at the time. The magnitude of FF significantly decreases with height (Fig. 12a) because $|\nabla \theta|$ decreases with height in our case. In addition, in the upper levels, the region of the significant FF near the cold front largely shifts northward. Overall, FF at the lowermost troposphere is found to be useful as an indicator for the frontal GW generation of $\mathrm{W} 1$ and $\mathrm{W} 3$. However, FF fails to indicate the generation of W2, where $|\nabla \theta|$ begins to decrease. Also, along the cold front, the significant FF is distributed on an overly broad area, compared to the regions of W4 and W5, which would make it difficult to approximate the location of GW generation by using the FF diagnostic. Further study on these points is required to improve the parameterization of frontal GWs.

\section{Summary}

The idealized baroclinic instability case of JW06 is simulated using the global version of WRF, and the characteristic spectra for the GWs generated in the baroclinic life cycle are investigated. In this simulation, the baroclinic wave is amplified largely in the lowermost troposphere, differing from the previous studies in which upper-level baroclinic waves have been emphasized. After the mature stage of the baroclinic wave (day 5) is reached, three groups of GWs (W1W3) appear at high latitudes around the surface trough. Their phase lines are generally aligned with the near-surface isen- tropic lines that are associated with the intrusion of the occluded front into the high-latitude trough. W1-W3 have horizontal wavelengths ranging from 40 to $400 \mathrm{~km}$ in the upper troposphere, which are similar to those in previous studies. The periods and vertical wavelengths have broad spectra (0.7-24 h and 2.9-9.8 km, respectively). During the upward propagation in the upper troposphere, they seem to undergo model diffusion and show significant dissipation near the tropopause.

At the breaking stage of the baroclinic wave when the midlatitude trough is isolated from the higher-latitude trough (day 7), two groups of quasi-stationary GWs (W4 and W5) appear above the midlatitude fronts around the isolated low. They have horizontal wavelengths of $60-400 \mathrm{~km}$. The vertical wavelengths of W4 and W5 (4.9-14 km) are larger than those of the GWs generated from the upper-tropospheric jet (e.g., Zhang, 2004). Because of the large vertical wavelengths, they undergo less diffusion than W1-W3.

The phase-velocity spectrum of W1-W3 exhibits an arcshaped structure (Fig. 7) that is characterized by a zero phase speed with respect to a reference frame moving eastward at $16-17 \mathrm{~ms}^{-1}$. This spectral structure is suggestive of GW generation by the occluded front intruding into the high-latitude trough moving at this speed. The phase-velocity spectrum of W4 and W5 is characterized by the dominance of very low phase-speed components, which can be explained by the GW generation due to the midlatitude stationary fronts at the surface. PS07 highlighted that the phase speed of the GWs in their simulations was the same as that of the baroclinic wave, as referred to in the introduction. In this context, our results for $\mathrm{W} 1-\mathrm{W} 5$ are also generally consistent with those of PS07, and it seems feasible to expect the peak of the phase-velocity spectrum of GWs by estimating the speed of the baroclinic jet-front systems. However, more case studies are necessary.

The phase-velocity analysis also gives some insights to the stratospheric propagation of the waves, although the waves in the simulation are dissipated by the artificial model diffusion. Considering the phase speeds of $\mathrm{W} 1-\mathrm{W} 3$, they are difficult to propagate to the stratosphere unless the midlatitude tropospheric jet is connected with the stratospheric winter jet at the northern edge of the tropospheric jet. However, the quasistationary W4 and W5 are able to propagate to the middle atmosphere in the wintertime without significant filtering.

The relation between the simulated GWs and the background (large-scale) frontogenesis function is investigated. The frontogenesis function seems to provide a rough indication of regions for some wave groups (W1 and W3) but not at all for W2. Also, significant values of the frontogenesis function are distributed on overly broad areas. There is no relationship between the amplitudes of GWs and frontogenesis function. Further study on the relation between the generation/characteristics of GWs and the frontogenesis function, as well as other large-scale diagnostics, is required. 
Acknowledgements. Y.-H. Kim and H.-Y. Chun were supported by the Korea Polar Research Institute (KOPRI, PE15090) and by the $\mathrm{R} \& \mathrm{D}$ project on the development of global numerical weather prediction systems of the Korea Institute of Atmospheric Prediction Systems (KIAPS), funded by the Korea Meteorological Administration (KMA).

Edited by: P. Haynes

\section{References}

Charron, M. and Manzini, E.: Gravity waves from fronts: parameterization and middle atmosphere response in a general circulation model, J. Atmos. Sci., 59, 923-941, doi:10.1175/15200469(2002)059<0923:GWFFPA>2.0.CO;2, 2002.

Choi, H.-J. and Chun, H.-Y.: Effects of convective gravity wave drag in the Southern Hemisphere winter stratosphere, J. Atmos. Sci., 70, 2120-2136, doi:10.1175/JAS-D-12-0238.1, 2013.

Eckermann, S. D. and Vincent, R. A.: VHF radar observations of gravity wave production by cold fronts over Southern Australi, J. Atmos. Sci., 50, 785-806, 1993.

Fritts, D. C. and Nastrom, G. D.: Sources of mesoscale variability of gravity waves. Part II: Frontal, convective, and jet stream excitation, J. Atmos. Sci., 49, 111-127, doi:10.1175/15200469(1992)049<0111:SOMVOG>2.0.CO;2, 1992.

Fritts, D. C. and Alexander, M. J.: Gravity wave dynamics and effects in the middle atmosphere, Rev. Geophys., 41, 1-64, doi:10.1029/2001RG000106, 2003.

Geller, M. A., Alexander, M. J., Love, P. T., Bacmeister, J., Ern, M., Hertzog, A., Manzini, E., Preusse, P., Sato, K., Scaife, A. A., and Zhou, T.: A comparison between gravity wave momentum fluxes in observations and climate models, J. Climate, 26, 6383-6405, doi:10.1175/JCLI-D-12-00545.1, 2013.

Gossard, E. E. and Hooke, W. H.: Waves in the Atmosphere, Elsevier, Amsterdam, 1975.

Guest, F. M., Reeder, M. J., Marks, C. J., and Karoly, D. J.: Inertiagravity waves observed in the lower stratosphere over Macquarie Island, J. Atmos. Sci., 57, 737-752, doi:10.1175/15200469(2000)057<0737:IGWOIT>2.0.CO;2, 2000.

Holton, J. R.: An Introduction to Dynamic Meteorology, Academic, San Diego, California, 1992.

Hoskins, B. J.: The mathematical theory of frontogenesis, Annu. Rev. Fluid Mech., 14, 131-151, doi:10.1146/annurev.fl.14.010182.001023, 1982.

Jablonowski, C. and Williamson, D. L.: A baroclinic instability test case for atmospheric model dynamical cores, Q. J. Roy. Meteor. Soc., 132, 2943-2975, doi:10.1256/qj.06.12, 2006.

Kim, S.-Y. and Chun, H.-Y.: Momentum flux of stratospheric gravity waves generated by Typhoon Ewiniar(2006), Asia-Pac. J. Atmos. Sci., 46, 199-208, doi:10.1007/s13143-010-0018-z, 2010.

Kim, Y.-H., Chun, H.-Y., Preusse, P., Ern, M., and Kim, S.-Y.: Gravity wave reflection and its influence on the consistency of temperature- and wind-based momentum fluxes simulated above Typhoon Ewiniar, Atmos. Chem. Phys., 12, 10787-10795, doi:10.5194/acp-12-10787-2012, 2012.

Kim, Y.-J., Eckermann, S. D., and Chun, H.-Y.: An overview of the past, present and future of gravity-wave drag parametrization for numerical climate and weather prediction models, Atmos.Ocean, 41, 65-98, doi:10.3137/ao.410105, 2003.

Miller, J. E.: On the concept of frontogenesis, J. Meteorol., 5, 169171, 1948.

Mirzaei, M., Zülicke, C., Mohebalhojeh, A. R., Ahmadi-Givi, F., and Plougonven, R.: Structure, energy, and parameterization of inertia-gravity waves in dry and moist simulations of a baroclinic wave life cycle, J. Atmos. Sci., 71, 2390-2414, doi:10.1175/JASD-13-075.1, 2014.

O'Sullivan, D. and Dunkerton, T. J.: Generation of inertiagravity waves in a simulated life cycle of baroclinic instability, J. Atmos. Sci., 52, 3695-3716, doi:10.1175/15200469(1995)052<3695:GOIWIA>2.0.CO;2, 1995.

Palmer, T. N., Shutts, G. J., and Swinbank, R.: Alleviation of a systematic westerly bias in general circulation and numerical weather prediction models through an orographic gravity wave drag parametrization, Q. J. Roy. Meteor. Soc., 112, 1001-1039, doi:10.1002/qj.49711247406, 1986.

Park, S.-H., Skamarock, W. C., Klemp, J. B., Fowler, L. D., and Duda, M. G.: Evaluation of global atmospheric solvers using extensions of the Jablonowski and Williamson baroclinic wave test case, Mon. Weather Rev., 141, 3116-3129, doi:10.1175/MWRD-12-00096.1, 2013.

Park, S.-H., Klemp, J. B., and Skamarock, W. C.: A comparison of mesh refinement in the global MPAS-A and WRF models using an idealized normal-mode baroclinic wave simulation, Mon. Weather Rev., 142, 3614-3634, doi:10.1175/MWR-D-14$00004.1,2014$.

Plougonven, R. and Snyder, C.: Inertia-gravity waves spontaneously generated by jets and fronts. Part I: Different baroclinic life cycles, J. Atmos. Sci., 64, 2502-2520, doi:10.1175/JAS3953.1, 2007.

Plougonven, R. and Zhang, F.: Internal gravity waves from atmospheric jets and fronts, Rev. Geophys., 52, 33-76, doi:10.1002/2012RG000419, 2014.

Plougonven, R., Teitelbaum, H., and Zeitlin, V.: Inertia gravity wave generation by the tropospheric midlatitude jet as given by the Fronts and Atlantic Storm-Track Experiment radio soundings, J. Geophys. Res., 108, 4686, doi:10.1029/2003JD003535, 2003.

Richter, J. H., Sassi, F., and Garcia, R. R.: Toward a physically based gravity wave source parameterization in a general circulation model, J. Atmos. Sci., 67, 136-156, doi:10.1175/2009JAS3112.1, 2010.

Sato, K., Tateno, S., Watanabe, S., and Kawatani, Y.: Gravity wave characteristics in the Southern Hemisphere revealed by a highresolution middle-atmosphere general circulation model, J. Atmos. Sci., 69, 1378-1396, doi:10.1175/JAS-D-11-0101.1, 2012.

Shakespeare, C. J.: Non-hydrostatic wave generation at strained fronts, J. Atmos. Sci., doi:10.1175/JAS-D-14-0294.1, online first, 2015.

Skamarock, W. C., Park, S.-H., Klemp, J. B., and Snyder, C.: Atmospheric kinetic energy spectra from global high-resolution nonhydrostatic simulations, J. Atmos. Sci., 71, 4369-4381, doi:10.1175/JAS-D-14-0114.1, 2014.

Snyder, C., Skamarock, W. C., and Rotunno, R.: Frontal dynamics near and following frontal collapse, J. Atmos. Sci., 50, 3194-3212, doi:10.1175/15200469(1993)050<3194:FDNAFF>2.0.CO;2, 1993. 
Song, I.-S. and Chun, H.-Y.: Momentum flux spectrum of convectively forced internal gravity waves and its application to gravity wave drag parameterization. Part I: Theory, J. Atmos. Sci., 62, 107-124, doi:10.1175/JAS3954.1, 2005.

Torrence, C. and Compo, G. P.: A practical guide to wavelet analysis, B. Am. Meteorol. Soc., 79, 61-78, 1995.

Uccellini, L. W. and Koch, S. E.: The synoptic setting and possible energy sources for mesoscale wave disturbances, Mon. Weather Rev., 115, 721-729, doi:10.1175/15200493(1987)115<0721:TSSAPE>2.0.CO;2, 1987.

Waite, M. L. and Snyder, C.: The mesoscale kinetic energy spectrum of a baroclinic life cycle, J. Atmos. Sci., 66, 883-901, doi:10.1175/2008JAS2829.1, 2009.
Wang, S. and Zhang, F.: Sensitivity of mesoscale gravity waves to the baroclinicity of jet-front systems, Mon. Weather Rev., 135, 670-688, doi:10.1175/MWR3314.1, 2007.

Zhang, F.: Generation of mesoscale gravity waves in uppertropospheric jet-front systems, J. Atmos. Sci., 61, 440-457, doi:10.1175/1520-0469(2004)061<0440:GOMGWI>2.0.CO;2, 2004.

Zhang, F., Wang, S., and Plougonven, R.: Uncertainties in using the hodograph method to retrieve gravity wave characteristics from individual soundings, Geophys. Res. Lett., 31, L11110, doi:10.1029/2004GL019841, 2004. 